\title{
Caracterização geotermobarométrica dos metabasitos de Cajamar (SP), Grupo São Roque, Cinturão Ribeira
}

\author{
Marcos Aurélio Farias de Oliveira ${ }^{1}$, Rodrigo Prudente de Melo², Antônio José Ranalli \\ Nardy ${ }^{1} \&$ Paola Bruno Arab ${ }^{3}$
}

\begin{abstract}
Resumo Rochas metamáficas, ortoderivadas, caracterizadas por assinaturas do tipo MORB e idades paleoproterozoicas ocorrem na região de Cajamar, centro leste do Estado de São Paulo, associadas a filitos, metarenitos e metacalcários da sequência metavulcano-sedimentar do Grupo São Roque, Faixa Ribeira Meridional. Para essas rochas, a associação de pico metamórfico é representada por actinolita-albita-epidotoclorita, típica de metamorfismo regional da fácies dos xistos verdes. Para melhor caracterizar os parâmetros de pressão e temperatura a que foram submetidas essas rochas, os principais minerais foram analisados por microssonda eletrônica. $\mathrm{O}$ metamorfismo não destruiu completamente a mineralogia primária dos basaltos. Microgabros originais e cristais de augita são registrados em muitos lugares, preservados junto à associação metamórfica. Eles permitem estimar as possíveis temperaturas ígneas entre 900 e $1.100^{\circ} \mathrm{C}$. O equilíbrio mineral para as paragêneses de pico metamórfico é observado apenas em algumas amostras, dificultando a obtenção desses valores. Além disso, um evento retrometamórfico, resultante de processo de cisalhamentos superimpostos, pode ter afetado este equilíbrio. Onde o equilíbrio é observado, principalmente nas ocorrências da porção sul da área, determinações de temperatura e pressão indicam valores de $487 \pm 42^{\circ} \mathrm{C}$ e $8,2 \pm 2,0 \mathrm{kbar}$, respectivamente, para o pico metamórfico. Outros valores de $\mathrm{T}$ e $\mathrm{P}$, menores que os de pico, foram também registrados nas porções central e norte da área e são: $450 \pm 68^{\circ} \mathrm{C}$ e $4,7 \mathrm{kbar}$ e $315 \pm 26^{\circ} \mathrm{C}$ e $3,0 \mathrm{kbar}$ e podem representar pontos onde o equilíbrio mineral não foi atingido ou corresponder a valores referentes ao evento de retrometamorfismo. Considerando esses resultados e, a trajetória metamórfica que eles representam, pode-se supor que o processo de exumação dessa área ocorreu por descompressão quase isotérmica.
\end{abstract}

Palavras-chave: Rochas metamáficas, metamorfismo regional de fácies xistos verdes, associação actinolitaalbita-epidoto-clorita, Grupo São Roque, Cinturão Ribeira Meridional.

Abstract Geothermobarometric characterization of metabasic rocks of Cajamar region (SP): São Roque Group, Ribeira Belt. Metamafic orthoderivate rocks, characterized by MORB signatures and paleoproterozoic ages occur in Cajamar region central east part of São Paulo State, Brazil. They are associated to philites, metasandstones and metalimestones of São Roque Group volcanosedimentary sequence, Southeastern portion of the Ribeira Belt. For the metamafic rocks the assemblage of metamorphic peak is represented by actinolitealbite-epidote-chlorite typical of regional metamorphism, greenschist facies. For a good characterization of $\mathrm{P}$ and $\mathrm{T}$ parameters of metamorphism microprobe analyses of main minerals were performed. Metamorphism did not destroy completely the primary mineralogy of original basalt and microgabbro, and augite crystals are registered in many samples, preserved together with metamorphic assemblage, and possibly indicate that the igneous temperatures of crystallization are between 900 and $1.100^{\circ} \mathrm{C}$. Textures of mineral equilibrium for the peak paragenesis are not always present in the studied samples. It may be partially caused by the superposition of retrometamorphic events that is a consequence of regional shearing process. Where the equilibrium is reached, chiefly in the occurrences in the south of the area temperature and pressure determinations indicate values close to $487 \pm 42^{\circ} \mathrm{C}$ and $8,2 \pm 2.0 \mathrm{kbar}$, respectively. Other values for $\mathrm{P}$ and $\mathrm{T}$ lower than that of the peak were also obtained in central and north portion of the area and they are: $450 \pm 68^{\circ} \mathrm{C}$ for T e $4.7 \mathrm{kbar}$ for $\mathrm{P}$ and $315 \pm 26^{\circ} \mathrm{C}$ for $\mathrm{T}$ and $3.0 \mathrm{kbar}$ for $\mathrm{P}$ and may indicate that the mineral equilibrium was not reached in these samples or that they represent the retrometamorphic event. As a concluding remark considering the metamorphic P-T path now obtained one can say that the exhumation process in this area occurred by isothermal decompression.

Keywords: Metamafic rocks, actinolite-albite-epidoto-chlorite assemblage, greenschist regional metamorphism, São Roque Group, Ribeira Belt, Southeastern Brazil.

INTRODUÇÃO A caracterização precisa dos parâmetros de metamorfismo regional em muitos cinturões de baixo grau, que ocorrem em áreas tropicais, torna-se geralmente complexa em função do estado de alteração que atinge a maioria das rochas. A determinação dos valores de temperatura e pressão é sempre muito difícil

1 - Departamento de Petrologia e Metalogenia, Instituto de Geociências e Ciências Exatas, Universidade Estadual Paulista, Rio Claro (SP), Brasil. E-mail: maurelio@rc.unesp.br, nardy@rc.unesp.br

2 - Programa de Pós-Graduação em Geologia Regional - IGCE - UNESP, Rio Claro (SP), Brasil. E-mail: rodrigopmel@gmail.com

3 - Programa de Pós-Graduação, Escola de Engenharia de São Carlos, São Carlos (SP), Brasil. E-mail: arab@sc.usp.br 
mesmo nos metassedimentos aluminosos ou arenosos, frequentemente muito alterados pelo intemperismo, onde, a associação quartzo-sericita-clorita-turmalina, em metapelitos, é indicativa de metamorfismo de fácies xistos verdes, porém, a ausência de minerais índices não permite a obtenção de valores numéricos de $\mathrm{P}$ e $\mathrm{T}$ satisfatórios. Nesse sentido, as rochas metamáficas, que podem ocorrer de forma preservada, em meio a esses metassedimentos, são importantes para determinações geotermobarométricas.

A associação actinolita-albita-epidoto-clorita, quartzo e água, no sistema $\mathrm{Na}_{2} \mathrm{O}-\mathrm{CaO}-\mathrm{FeO}-\mathrm{MgO}-$ $\mathrm{Al}_{2} \mathrm{O}_{3}-\mathrm{SiO}_{2}-\mathrm{H}_{2} \mathrm{O}$ é muito comum nos metabasitos que ocorrem encaixados em sequências de metamorfismo regional de baixo grau em diversas regiões do mundo. Nessas rochas merece destaque a presença, sempre constante, do anfibólio cálcico, tipo actinolita, que é um importante indicador das condições de $\mathrm{T}$ e $\mathrm{P}$ de metamorfismo (Okamoto \& Toriumi 2001, 2004) e que segundo esses autores indicam temperaturas de estabilidade que podem atingir valores próximo a $500^{\circ} \mathrm{C}$ e pressões que podem alcançar 6,5 kbar.

Os metassedimentos proterozoicos de fácies xistos verdes do Grupo São Roque, que ocorrem no Pré-Cambriano do Estado de São Paulo, contêm numerosas intercalações de rochas metamáficas, atribuídas ao metamorfismo de rochas basálticas e, que tiveram grande importância, no desenvolvimento e evolução dessa bacia.

Um exemplo importante disso são as ocorrências de metamáficas da região de Cajamar-Jordanésia, objeto do presente estudo, onde são registrados diversos corpos representados por tipos bem preservados de epidoto-actinolita xistos ou fels, metabasalto, metadiabásio, metamicrogabro e metatraquibasalto e que se mostram apropriados a estudos das transformações metamórficas. Esses corpos acham-se inseridos em metassedimentos que são metacalcários, filitos, quartzo filitos, com intercalações de metarenitos e que no conjunto constituem a Bacia São Roque (Figs. 1 e 2).

Desta forma, o presente artigo visa fornecer subsídios para um melhor conhecimento das transformações metamórficas ocorridas nessas rochas, bem como definir os intervalos de $\mathrm{P}$ e $\mathrm{T}$ em que elas foram geradas, utilizando principalmente os dados de química mineral.

SITUAÇÃO GEOLÓGICA O Grupo São Roque, juntamente com o Grupo Serra do Itaberaba, são parte integrante da porção central do Cinturão de Dobramentos Ribeira de Almeida et al. (1973), no Estado de São Paulo (Fig. 1). Mais especificamente constituem a Faixa de Dobramentos Apiaí de Hasui (1975) e Hasui et al. (1980), ou Domínio São Roque (Campos Neto \& Figueiredo 1995). O Domínio São Roque é constituído pelas sequências vulcano-sedimentares dos Grupos São Roque e Serra do Itaberaba, de baixo a médio grau metamórfico e idades paleo a neoproterozoicas (Juliani et al. 1986, Juliani \& Beljavskis 1995, Hackspacher et al. 2000, Juliani et al. 2000).
A base geológica utilizada para situar as unidades litológicas, bem como os corpos de metamáficas dos Grupos São Roque e Serra do Itaberaba, na região de Cajamar-Jordanésia, tem como fonte os levantamentos geológicos realizados por diversos autores entre os quais citamos: Coutinho (1980), Carneiro et al. (1984, 1985), Batista et al. (1987), Santoro et al. (1988), Martin (2000), Teixeira \& Gaucher (2004). Os dados disponíveis na literatura foram revistos e detalhados com novos estudos de campo realizados dentro da presente pesquisa e são apresentados na figura 2 .

$\mathrm{Na}$ área de estudo, representada pelo mapa geológico da figura 2, são encontradas rochas dos Grupos São Roque e Serra do Itaberaba, além de granitos intrusivos. O Grupo Serra do Itaberaba é constituído por xistos diversos, com destaque para estaurolita-cianita xistos, com intercalações de anfibolitos. O Grupo São Roque, na região de Cajamar, é representado por uma sequência basal constituída por filito, metarenito e metamicroconglomerado da Formação Estrada dos Romeiros e uma sequência superior representada por filito, metacalcário e metabasitos da Formação Pirapora (Bergmann 1988). Completando as unidades litológicas da área estão presentes também os corpos graníticos de Tico-Tico, a leste, e de Ponunduva, a oeste. Além disso, do ponto de vista estrutural, merece destaque a Zona de Cisalhamento de Jundiuvira, de caráter regional, que atravessa o canto oeste da área, no sentido NE-SW.

Os metabasitos constituem vários corpos, alongados segundo a foliação principal NE-SW, associados preferencialmente às unidades que contêm os filitos e metacalcários, com contatos mascarados pelo espesso manto de intemperismo. Os corpos de maiores dimensões ocorrem mais para o sul da área, enquanto que para norte as ocorrências são de menor expressão. São rochas originalmente magmáticas e o metamorfismo as afetou de maneira desigual, sendo que as ocorrências da área central são as menos transformadas e, mantêm preservadas, as texturas e a composição mineral dos protolitos magmáticos.

Com relação ao ambiente de formação dessa sequência vulcano-sedimentar, Figueiredo et al. (1982), Bergmann (1988), Lazzari (1987), Sadowski \& Tassinari (1991), Hackspacher et al. (2000), Juliani et al. (2000) consideram a sua formação num ambiente do tipo "back-arc" ensiálico e, mais recentemente Tassinari et al. (2001) interpretam parte da sequência de metamáficas, ocorrendo na região próxima de Pirapora do Bom Jesus, como correspondente a um ofiolito.

Publicações recentes mostram que a idade do Grupo São Roque é ainda um problema controvertido, com valores neoproterozoicos obtidos por Hackspacher et al. (2000), em torno de $628 \pm 9 \mathrm{Ma}(\mathrm{U} / \mathrm{Pb}$ em monazita de rocha metabásica) e idades de $1790 \pm 14$ Ma, obtidas em metarriolitos, que ocorrem associados a uma sequência de filitos, xistos e metarenitos, segundo Van Shumus et al. (1986), por U/Pb em zircão, idade essa que foi interpretada pelos autores como sendo correspondente à idade da porção basal do Grupo São Roque. Para a região de Cajamar, ora estudada, Oliveira et 
al. (2008) apresentam idade $\mathrm{U} / \mathrm{Pb}$ em zircão de metamicrogabro de 1,75 \pm 40 Ma. Já o Grupo Serra do Itaberaba é tido como mesoproterozoico com idade aproximada de $1395 \pm 10 \mathrm{Ma}$, obtida por Juliani et al. (2000), também usando $\mathrm{U} / \mathrm{Pb}$ em zircão de metarriolito.

Já os granitos intrusivos que ocorrem na área têm idades neoproterozoicas e são do tipo crustal. Töpfner (1996) apresenta valores U/Pb em zircão de $625 \pm 18$ Ma para o granito Tico-Tico.

Do ponto de vista geoquímico, segundo Oliveira et al. (2002), as rochas metamáficas de
Cajamar-Jordanésia evidenciam uma origem a partir de protolitos ígneos toleíticos (basalto, diabásio, gabro), subalcalinos, com afinidades de basaltos de cadeia meso-oceânica (MORB). Teores muito baixos de elementos incompatíveis (Rb: 2-8 ppm; Y: 14-77 ppm; $\mathrm{Nb}$ : 2-10 ppm; Th: 0,18-1,42 ppm; Ta: 0,01-075 ppm; Hf: 1,0-2,4 ppm; La: 2,28-24,4 ppm e Ce: 6,02-29,2) constituem característica importante dessas rochas e corroboram a sua natureza do tipo MORB, como toleiítos de fundo oceânico.

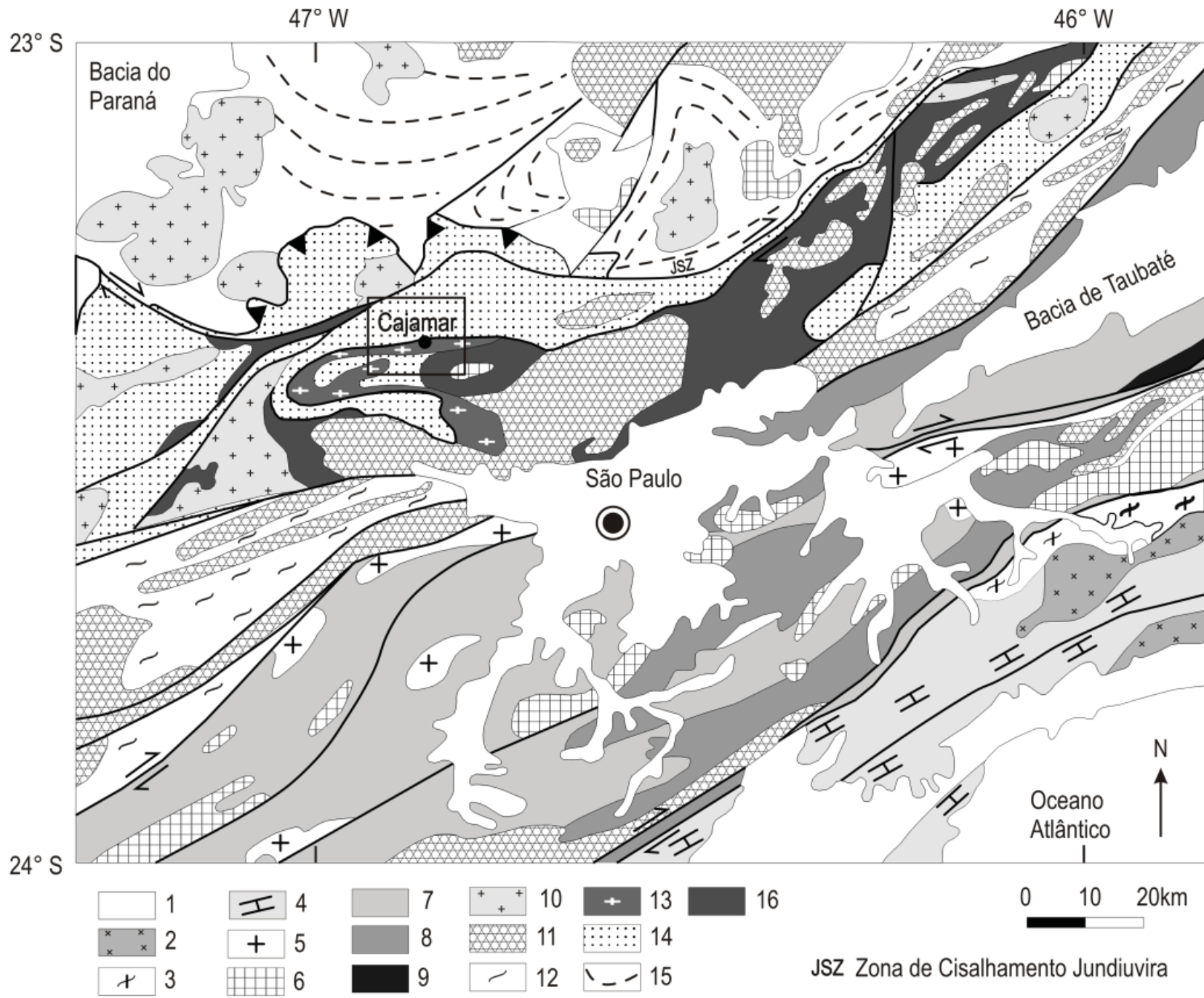

Figura 1 - Mapa geológico da porção sudeste do Estado de São Paulo (porção central do Cinturão Ribeira). Modificado de Campos Neto (2000). 1. Coberturas Fanerozoicas. 2. Suíte granitoide e charnockítica metaluminosa do Terreno Serra do Mar. 3. Migmatitos com sillimanita e granada com resistatos de quartzito do Terreno Serra do Mar. 4. Migmatitos metaluminosos do Terreno Serra do Mar. 5. Zona de cisalhamento relacionada ao granito metaluminoso do Terreno Juiz de Fora. 6. Granito peraluminoso do Terreno Juiz de Fora. 7. Quartzitos e quartzitos xistosos rítmicos do Complexo Embu. 8. Sequência metavulcano-sedimentar do Complexo Embu. 9. Gnaisses cinzentos de idade Arqueana-Paleoproterozoica do Complexo Embu. 10. Granitos tipo A (575-580 Ma) do Terreno Apiaí. 11. Hornblenda-biotita granito (630 Ma) e granitos metaluminosos (610-605 Ma). 12. Xistos e gnaisses do terreno Apiaí. 13. Associação de quartzitos, calcários com biohermas e rochas metavulcânicas, continentais e de águas rasas do Grupo São Roque. 14. Metarritmitos, quartzitos, metacalcários e metabasaltos com estruturas de pillow-lavas do Grupo São Roque, Cinturão de Dobramento Ribeira - Domínio São Roque. 15. Sillimanita-granada migmatitos do Complexo Piracaia. 16. Grupo Serra do Itaberaba (Ectasiano), Cinturão de dobramentos Ribeira, Domínio São Roque. 


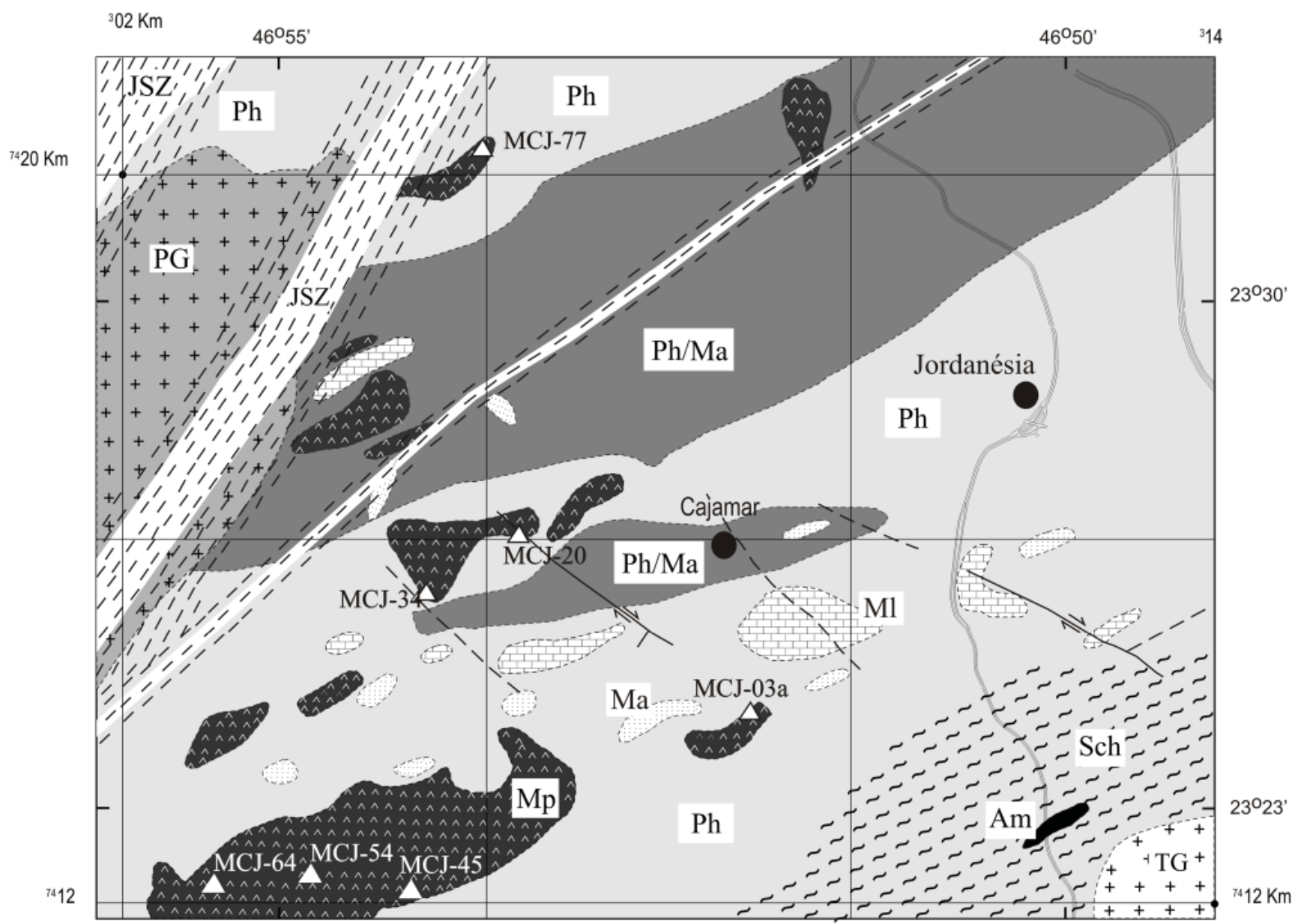

${ }^{3} 02$

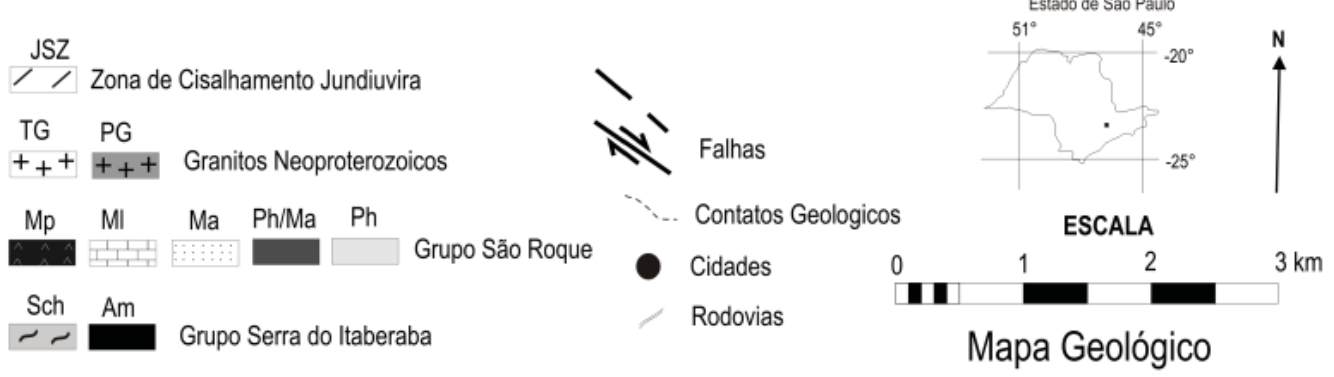

Figura 2 - Mapa geológico da região de Cajamar. ZCJ - Zona de Cisalhamento de Jundiuvira; GT - Granito peraluminoso de Tico-Tico (625 Ma); GP - Granito metaluminoso de Ponunduva; Grupo São Roque: Mp - Rochas metamáficas; Ml - Metacalcários; Ma - Metarenito; Ph - Filito; Grupo Serra do Itaberaba: Sch - Mica xistos; Am - Anfibolitos.

ASSOCIAÇÕES MINERAIS As rochas metamáficas estudadas são ortoderivadas e desta forma, além das feições que resultam dos processos metamórficos, registram ainda muitas características herdadas das rochas magmáticas que representam seus protolitos, pois as transformações metamórficas nem sempre destruíram totalmente a mineralogia e as texturas existentes o que é evidenciado quando se estudam os diversos corpos que ocorrem nessa área. Assim, em muitos locais são encontrados clinopiroxênios primários, bem como estruturas e texturas magmáticas ainda preservadas, tais como estruturas vesiculares, amigdaloidais e tufáceas e texturas intergranulares, subofíticas, porfiríticas e cumuláticas.
Nestas últimas, os cristais de clinopiroxênio (cumulus) estão envolvidos por matriz rica em plagioclásio, que com o metamorfismo foi transformado em albita.

As rochas que passaram por transformações metamórficas mais intensas exibem estruturas predominantemente maciças (fels) e mais raramente foliadas. A granulação é fina a média, com a dimensão dos cristais atingindo até $3 \mathrm{~mm}$ com texturas granoblásticas decussadas, com a maioria dos cristais xenomórficos e mais raramente idiomórficos. Considerando que toda essa área foi afetada por forte processo de cisalhamento regional, de modo geral essas rochas apresentam-se bastante fraturadas e crenuladas, com deformações do 
tipo "kink", exibindo texturas cataclásticas e miloníticas que se superpõem à decussada.

Actinolita, albita, epidoto, clorita, titanita, quartzo e calcita são os minerais metamórficos presentes em todas as rochas, ocorrendo em proporções variadas em cada uma delas. Completa a mineralogia de alguns tipos o clinopiroxênio (Fig. 3, fotomicrografias A e B).

O clinopiroxênio constitui cristais subidiomórficos, corroídos e fraturados e que podem medir até $5 \mathrm{~mm}$ de comprimento e tem sua presença registrada apenas em algumas amostras. São cristais, muitas vezes geminados, de cor verde pálido ou marrom, que aparecem quase sempre cercados por actinolita e, mais raramente, por epidoto e clorita (Fig. 3, fotomicrografia C).

A actinolita é o mineral metamórfico mais abundante nessas rochas e pode constituir porfiroblastos, geralmente esqueletiformes, quando então atingem até 6 $\mathrm{mm}$ de comprimento, com bordas corroídas, esfarrapadas ou, então, juntamente com o epidoto, substituindo total ou parcialmente o piroxênio, às vezes como pseudomorfos, incluindo, vez por outra, restos desse mineral. Apresenta-se também com formas aciculares preenchendo interstícios ou fraturas. Exibe forte pleocroismo com cores que variam de verde pálido a incolor. Alguns cristais mostram-se zonados, feição destacada pela variação das cores do pleocroismo.

A albita ocorre substituindo totalmente as ripas de plagioclásio. Ocorre também de forma intersticial, associada ao epidoto, como produto da recristalização metamórfica.

$\mathrm{O}$ epidoto, e mais raramente clinozoisita, ocorre de várias formas que vão desde porfiroblastos idiomórficos, passando por agregados de vários cristais também idiomórficos (Fig. 3, fotomicrografia D) até pequenos cristais associados à actinolita e à clorita ou preenchendo amígdalas. Também ocorre na matriz dessas rochas, associado à albita, ou às vezes em fraturas e zonas cisalhadas.
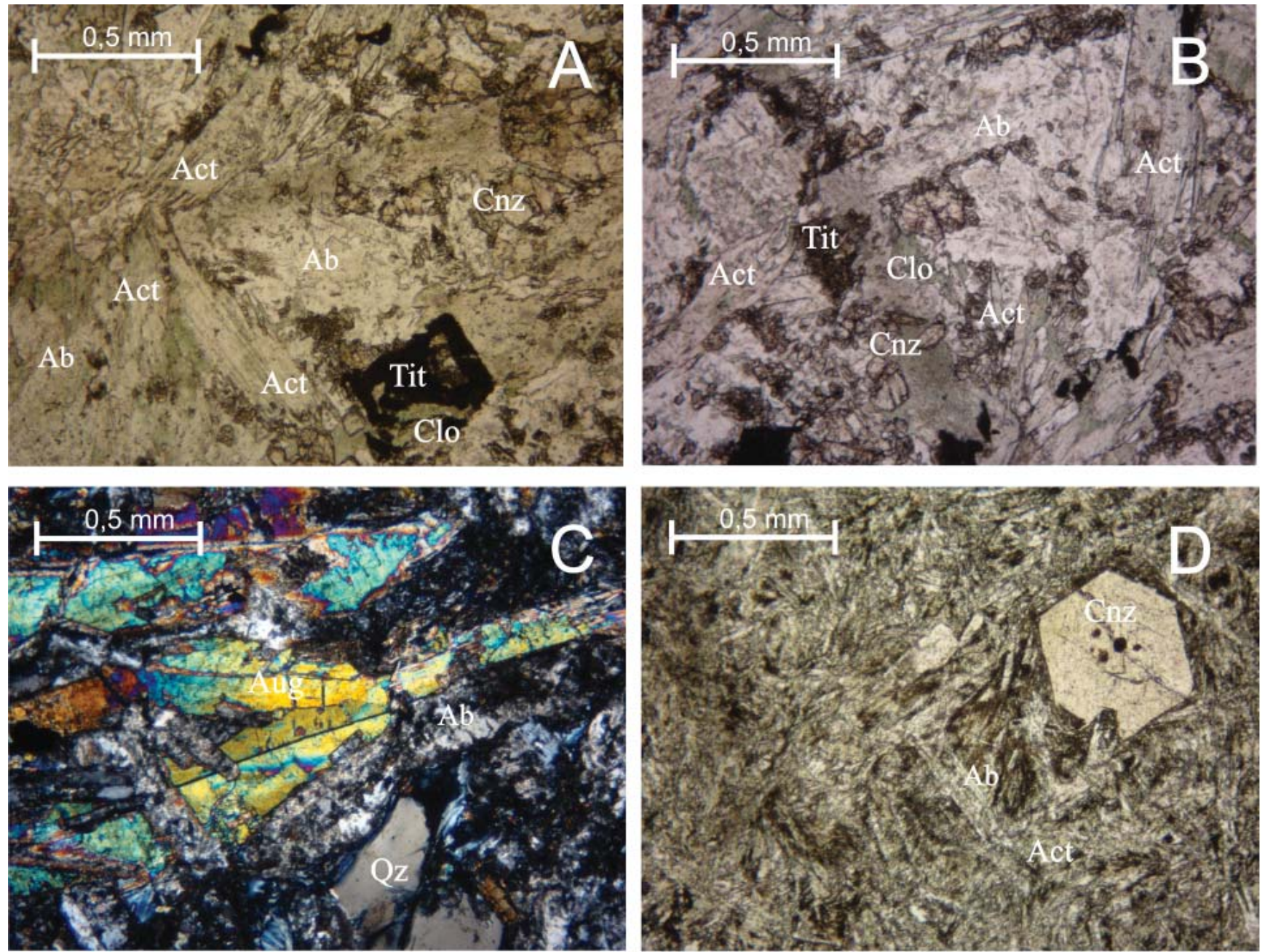

Figura 3 - Fotomicrografias exibindo feições de destaque das rochas metabásicas. A e B. Actinolita fels: associação de actinolita (Act), albita (Ab), clorita (Clo), epidoto (Cnz) e titanita (Tit), preservando textura intergranular herdada (amostra 3a.) C. Metamicrogabro. Cristal de augita (Aug) geminado, circundado por albita. Observa-se as antigas texturas intergranular e ofítica ainda preservadas (amostra 20a). D. Metatraquibasalto. Associação albita-actinolita-epidoto, com destaque para porfiroblasto idiomórfico de epidoto, incluso em matriz que preserva a textura traquítica primária (amostra 64). 
Quanto à clorita, observa-se que ela aparece associada à actinolita, como produto da transformação do piroxênio e de forma intersticial, em conjunto com o epidoto. Pode também estar preenchendo fraturas ou vesículas, sendo que em algumas amostras os teores desse mineral são muito baixos. Em porções fraturadas e cisalhadas, a clorita pode recristalizar-se, estando nesse caso associada ao epidoto.

Pelas feições texturais, estruturais e mineralógicas as rochas metamáficas podem ser classificadas petrograficamente como epidoto-actinolita xistos ou fels, metabasalto, metadiabásio, metamicrogabro, metatraquibasalto e metatufo. Assim, para o epidoto-actinolita xisto ou fels predominam actinolita, epidoto, albita e clorita, sendo raramente encontrados cristais preservados de clinopiroxênio, que por sua vez são frequentes nos metabasitos, acompanhados por albita, que substitui o plagioclásio como pseudomorfos, além da actinolita, epidoto, clorita, titanita, calcita e quartzo. O único tipo que contém feldspato potássico, que nesse caso é de origem magmática, é o metatraquibasalto (Fig. 3, fotomicrografia D). Já o metatufo é de ocorrência bastante rara e quase sempre é encontrado muito intemperizado.

Assim, para essas rochas, tem-se uma associação magmática ainda preservada, representada nesse conjunto de rochas pelo clinopiroxênio e, eventualmente ortoclásio, e uma associação metamórfica constituída de actinolita, clinozoisita, clorita, albita, titanita, calcita e quartzo, presente em praticamente todas as amostras estudadas nessa área. Essa associação, que pode ser encontrada muitas vezes em equilíbrio, parece representar o pico metamórfico para o conjunto vulcano-sedimentar de fácies xistos verdes do Grupo São Roque.

O equilíbrio metamórfico entre os minerais nem sempre é atingido e, quando presente, envolve actinolita, albita e epidoto, podendo ou não aparecer associada à clorita. Nesse caso, o contato entre os cristais nem sempre é retilíneo, variando com as dimensões de cada mineral (Fig. 3, fotomicrografias 1 e 2). Na realidade, um dos fatores que dificulta a observação do equilíbrio da paragênese mineral de pico metamórfico é o processo de cisalhamento superposto, ao qual se associa forte cataclase e fraturamento, levando à recristalização de alguns minerais como epidoto e clorita.

QUÍMICA MINERAL Para os estudos de química mineral foram selecionadas oito amostras de rochas metamáficas, sendo quatro de epidoto-actinolita xisto ou fels, duas de metabasalto, uma de metamicrogabro e uma última do metatraquibasalto. Para isso, procurou-se evitar as amostras mais afetadas pelos processos de deformação que ocorreram posteriormente ao evento principal de metamorfismo. As análises foram obtidas por microssonda eletrônica, utilizando um equipamento marca Jeol JXA 86 do Laboratório de Microssonda Eletrônica do IGc/USP, com as seguintes condições de análise: corrente de aceleração do feixe de elétrons de $20 \pm 0,1 \eta \mathrm{A}$, tensão de $15 \mathrm{kV}$ e feixe de elétrons de 5 $\mu \mathrm{m}$ (de diâmetro), exceto para os feldspatos, para os quais foi utilizado um feixe de $10 \mu \mathrm{m}$ (de diâmetro). Silicatos naturais foram usados como padrões para todos os elementos.

Os minerais analisados são: anfibólio, epidoto, feldspatos, clorita, titanita e piroxênio, sendo que, pela abundância relativa, o maior número de análises foi feito em cristais de anfibólio. A maioria das análises foi realizada em pequenos cristais, tendo em vista a granulometria fina da maior parte das amostras e, nesse caso, as medidas foram feitas no centro desses cristais. Em cristais de piroxênio e epidoto foi possível, algumas vezes, analisar centro e borda.

Anfibólio $\mathrm{O}$ anfibólio analisado ocorre como cristais subidiomórficos, por vezes esqueletiformes, com bordas corroídas, associado à albita e epidoto ou nas bordas de piroxênio. Os resultados analíticos, juntamente com a fórmula estrutural, aparecem na tabela 1 , sendo o cálculo feito na base de 23 átomos de oxigênio. Usando a classificação de Leake et al. 1997, esses anfibólios caem no campo da actinolita, confirmando, assim, as observações petrográficas e mostrando a boa homogeneidade composicional desse mineral em toda a área estudada. A figura 4 mostra os pontos projetados no diagrama TSi x Mg/Mg+Fe de Leake et al. 1997, onde fica clara a variação da razão $\mathrm{Mg} / \mathrm{Mg}+\mathrm{Fe}$ entre 0,60 e 0,75 .

Feldspatos Os resultados com a composição química dos feldspatos e o cálculo da fórmula estrutural podem ser vistos na tabela 2 . Os dados foram projetados no diagrama Or-Ab-An, com o cálculo da fórmula estrutural realizado na base de 32 oxigênios.

Pela figura 5 observa-se que a maioria dos feldspatos analisados corresponde ao campo da albita, sendo que, apenas a amostra de metatraquibasalto, contém, além da albita, feldspato potássico, do tipo ortoclásio, com teores variados da molécula sódica. Como mencionado na caracterização petrográfica, apesar de ainda

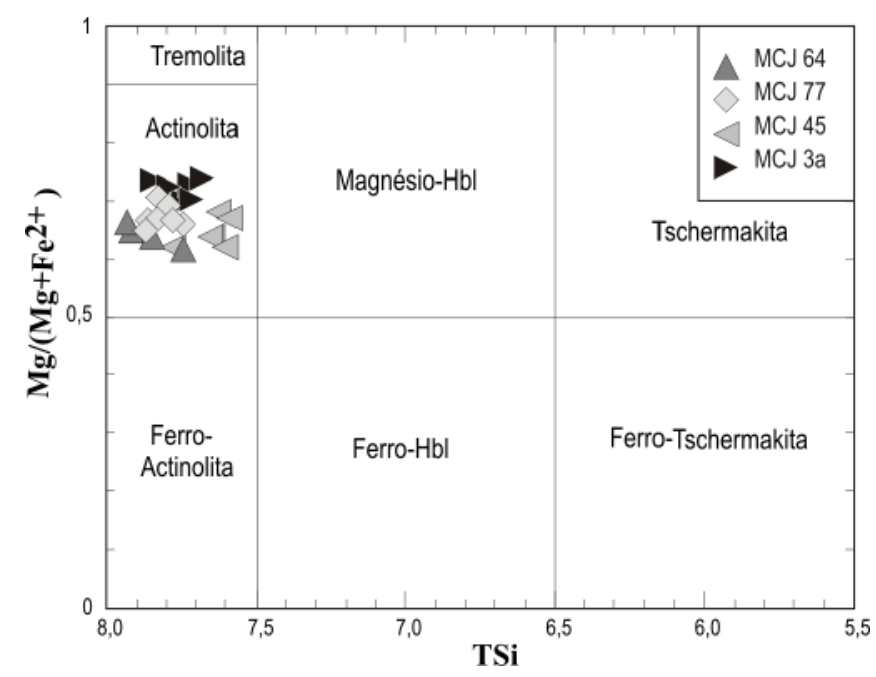

Figura 4 - Diagrama de Leake et al. (1977) de classificação dos anfibólios. Os cristais analisados caem no campo da actinolita. 
preservarem a forma do plagioclásio, confirma-se, pelas análises na microssonda, que esses minerais foram totalmente substituídos por albita.

Piroxênio Foram analisados cristais de diversos tamanhos, de 0,5 a $5 \mathrm{~mm}$, geralmente fraturados e corroídos e, muitas vezes, parcialmente substituídos por actinolita, epidoto ou clorita. Medidas de centro e borda dos cristais, mesmo dos maiores, indicam que há pouca variação na composição desses minerais, mas quando existe, revela um aumento do teor de cálcio nas bordas e de magnésio no núcleo (Fig. 6).

A fórmula estrutural desses minerais foi calculada na base de 6 átomos de oxigênio e os resultados foram projetados no diagrama de Morimoto (1988), com base nas porcentagens das moléculas de wollastonita, enstatita e ferrossilita (Wo-En-Fs). Segundo o diagrama, as amostras analisadas concentram-se, principalmente, no campo da augita cálcica, com alguns pontos no campo do diopsídio (Tab. 3).

Epidoto $\mathrm{O}$ epidoto é mineral presente em praticamente todas as amostras das rochas metamáficas da área estudada, ocorrendo como cristais ora idiomórficos, ora subidiomórficos e ora xenomórficos de tamanho variado, milimétricos a submilimétricos ou na forma de minúsculos cristais preenchendo fraturas ou impregnando os feldspatos. Foram feitas análises dos cristais maiores que ocorrem em associação com actinolita e clorita, possivelmente em equilíbrio metamórfico. Os resultados das análises, assim como a fórmula estrutural, estão na tabela 4. Pode-se observar pelos dados apresentados que esse mineral é rico em $\mathrm{Ca}$ e $\mathrm{Al}$ e principalmente $\mathrm{em} \mathrm{Fe}^{+3}$, o que o caracteriza como epidoto. Foram feitas medidas de centro e borda em alguns cristais, indicando variações nas relações entre $\mathrm{Ca}, \mathrm{Al}$ e $\mathrm{Fe}^{+3}$, sendo que o $\mathrm{Fe}^{+3}$ diminui do centro para a borda, em relação ao cálcio e ao alumínio, podendo, neste caso, haver enriquecimento na molécula de clinozoisita nas bordas dos cristais.

Clorita Este mineral é o que apresenta as maiores dificuldades para a análise, considerando suas dimensões diminutas e contornos irregulares. Foram investigados cristais geralmente submilimétricos, muitas vezes na forma de agregados, quase sempre associados ao epidoto. Nessas condições, fica difícil distinguir se os cristais analisados eram do metamorfismo principal ou se eram recristalizados. Os resultados e a fórmula estrutural desse mineral constam da tabela 5. Por eles, observa-se que quase todas as amostras analisadas concentram-se no limite entre a corundofilita e ripidolita, evidenciando maiores concentrações de $\mathrm{MgO}$ na amostra MCJ $3 \mathrm{a}$ e de $\mathrm{FeO}$ e $\mathrm{Al}_{2} \mathrm{O}_{3}$ nas amostras MCJ 45 e MCJ 77.

Titanita Os resultados das análises de titanita (três análises) evidenciam teores de $\mathrm{TiO}_{2}$ entre 35,4 e 38,6\%, de $\mathrm{CaO}$ entre 27,1 e $28,5 \%$ e de $\mathrm{SiO}_{2}$ entre 30,0 e $30,6 \%$. Foram detectadas também pequenas concentrações de $\mathrm{Al}_{2} \mathrm{O}_{3}$ entre 1,5 e $3,5 \%$ e de $\mathrm{Fe}_{2} \mathrm{O}_{3}$ entre 0,84 e $3,6 \%$.

CONDIÇÕES DE PRESSÃO E TEMPERATURA Temperaturas primárias dos metabasitos Como mencionado no item anterior, os protolitos das rochas metamáficas (basalto, diabásio e microgabro) são de natureza ígnea básica, constituídos essencialmente por plagioclásio e clinopiroxênio (augita) dos quais apenas o segundo ainda está preservado em diversos exemplares, pois o plagioclásio acha-se transformado em albita. Os dados de microssonda revelam que o clinopiroxênio é uma augita cálcica. Esse resultado, bem como a boa situação de preservação, a ausência de exsoluções, apesar do metamorfismo por que passou, mantendo inclusive as geminações de caráter primário, permite sua utilização como geotermômetro e

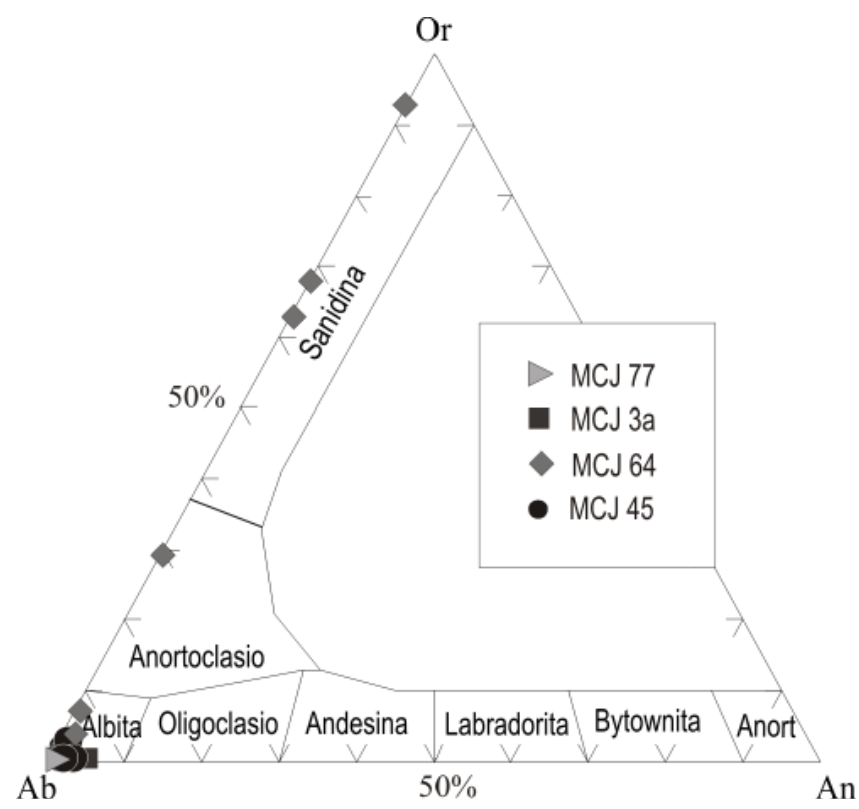

Figura 5 - Diagrama An-Ab-Or para os feldspatos analisados.

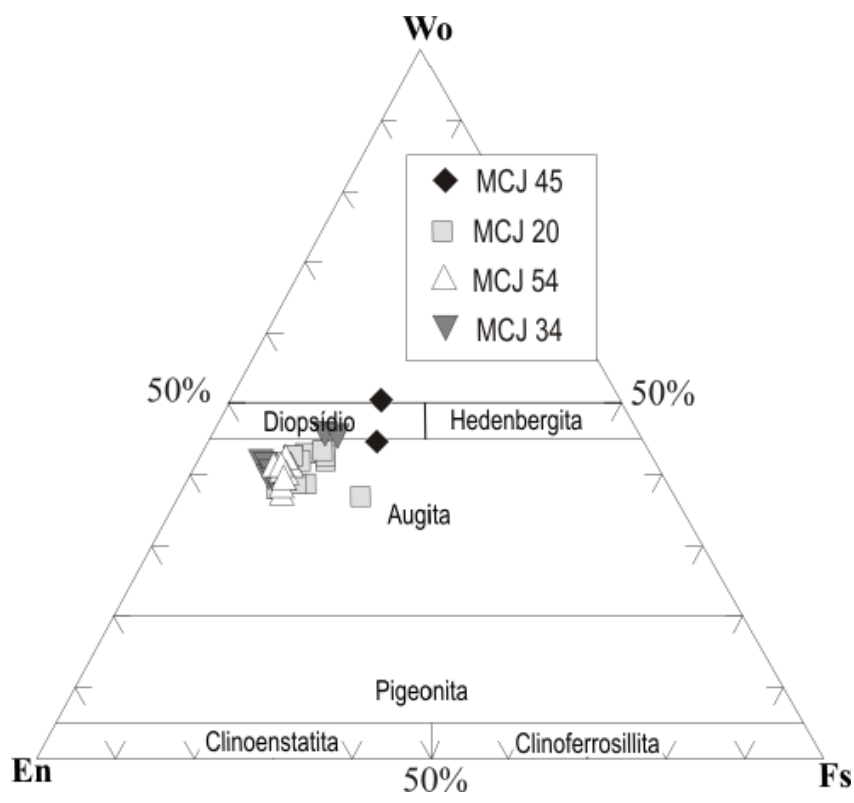

Figura 6 - Diagrama Wo-En-Fs para os piroxênios analisados. Segundo Morimoto (1988). 
pode fornecer valores de temperatura de cristalização bastante aproximados para essas rochas. Para obtenção desses parâmetros, os dados químicos desse mineral foram projetados no tetraedro de Lindsley (1983), como pode ser visto na figura 7.

Os resultados obtidos indicam temperaturas entre 1.100 e $800^{\circ} \mathrm{C}$ (para $\mathrm{P}=1 \mathrm{kbar}$ ), com a maioria das amostras no intervalo entre 1.100 e $900^{\circ} \mathrm{C}$, que são temperaturas características de cristalização dos basaltos.

Temperaturas e pressões de metamorfismo As rochas metamáficas de Cajamar apresentam como minerais típicos do metamorfismo principal a que estiveram submetidas: anfibólio cálcico (actinolita), albita, epidoto, clorita, titanita, quartzo e calcita, existindo uma recristalização de clorita e epidoto, o que caracteriza um retrometamorfismo ligado ao processo de deformação, posterior ao evento de metamorfismo principal, que gerou diversas zonas de cisalhamento.

Para os cálculos de temperatura e pressão utilizaram-se os softwares PTMAFIC e THERMOCALC, versão 3.2, de Powell \& Holland (1988).

Antes, porém, foram feitas estimativas, utilizando alguns geotermômetros e geobarômetros, que dão indicações referentes ao metamorfismo de rochas máficas.

O geotermômetro de Spear (1980) permite calcular as temperaturas a partir do equilíbrio entre anfibólio e plagioclásio. Para os cálculos foram utilizadas as análise químicas de actinolita e de albita, empregando-se o software PTMAFIC. Os resultados indicam temperaturas entre 300 e $420^{\circ} \mathrm{C}$.

Também utilizando o programa PTMAFIC pode-se aplicar o geotermômetro de Blundy \& Holland (1990), que também considera o equilíbrio entre plagioclásio e anfibólio. Os valores de temperatura obtidos

Tabela 1 - Análises de anfibólios das rochas metamáficas.

\begin{tabular}{|c|c|c|c|c|c|c|c|c|}
\hline Amostra & MCJ 3a & MCJ $3 a$ & MCJ 77 & MCJ 77 & MCJ 77 & MCJ 45 & MCJ 45 & MCJ 45 \\
\hline & $\mathrm{C}$ & $\mathrm{C}$ & $\mathrm{C}$ & $\mathrm{C}$ & $\mathrm{C}$ & $\mathrm{C}$ & $\mathrm{C}$ & $\mathrm{C}$ \\
\hline $\mathrm{SiO}_{2}$ & 53,90 & 54,90 & 54,55 & 55,58 & 54,78 & 53,36 & 52,76 & 52,97 \\
\hline $\mathrm{TiO}_{2}$ & 0,00 & 0,03 & 0,09 & 0,05 & 0,08 & 0,06 & 0,06 & 0,00 \\
\hline $\mathrm{Al}_{2} \mathrm{O}_{3}$ & 2,34 & 2,32 & 2,06 & 1,35 & 1,48 & 2,74 & 3,10 & 2,97 \\
\hline $\mathrm{FeO}$ & 12,94 & 12,34 & 13,47 & 13,38 & 13,60 & 14,32 & 14,38 & 15,09 \\
\hline $\mathrm{Cr}_{2} \mathrm{O}_{3}$ & 0,00 & 0,00 & 0,00 & 0,00 & 0,00 & 0,00 & 0,00 & 0,00 \\
\hline $\mathrm{MnO}$ & 0,10 & 0,19 & 0,20 & 0,28 & 0,23 & 0,23 & 0,21 & 0,19 \\
\hline $\mathrm{MgO}$ & 15,80 & 16,30 & 15,20 & 15,90 & 15,60 & 14,90 & 14,11 & 14,41 \\
\hline $\mathrm{CaO}$ & 12,96 & 12,93 & 13,24 & 12,96 & 13,01 & 12,93 & 12,93 & 12,80 \\
\hline $\mathrm{Na}_{2} \mathrm{O}$ & 0,24 & 0,26 & 0,12 & 0,08 & 0,10 & 0,27 & 0,37 & 0,31 \\
\hline $\mathrm{K}_{2} \mathrm{O}$ & 0,09 & 0,12 & 0,03 & 0,02 & 0,04 & 0,12 & 0,15 & 0,09 \\
\hline $\mathrm{F}$ & 0,09 & 0,00 & 0,06 & 0,00 & 0,03 & 0,00 & 0,16 & 0,02 \\
\hline $\mathrm{Cl}$ & 0,02 & 0,00 & 0,01 & 0,00 & 0,00 & 0,00 & 0,01 & 0,00 \\
\hline Total & 98,47 & 99,39 & 99,03 & 99,61 & 98,95 & 98,92 & 98,24 & 98,85 \\
\hline $\mathrm{Si}$ & 7,70 & 7,74 & 7,78 & 7,84 & 7,80 & 7,63 & 7,65 & 7,60 \\
\hline $\mathrm{Al}$ & 0,31 & 0,27 & 0,23 & 0,16 & 0,20 & 0,37 & 0,36 & 0,40 \\
\hline $\mathrm{Al}$ & 0,09 & 0,12 & 0,12 & 0,06 & 0,04 & 0,09 & 0,17 & 0,10 \\
\hline $\mathrm{Fe}^{3+}$ & 0,15 & 0,10 & 0,03 & 0,11 & 0,13 & 0,20 & 0,03 & 0,23 \\
\hline $\mathrm{Ti}$ & 0,00 & 0,00 & 0,01 & 0,01 & 0,01 & 0,01 & 0,01 & 0,00 \\
\hline $\mathrm{Mg}$ & 3,36 & 3,42 & 3,23 & 3,34 & 3,31 & 3,18 & 3,05 & 3,08 \\
\hline $\mathrm{Fe}^{2+}$ & 1,39 & 1,36 & 1,58 & 1,47 & 1,49 & 1,52 & 1,71 & 1,58 \\
\hline $\mathrm{Mn}$ & 0,01 & 0,02 & 0,02 & 0,03 & 0,03 & 0,03 & 0,03 & 0,02 \\
\hline $\mathrm{Ca}$ & 1,98 & 1,95 & 2,02 & 1,96 & 1,98 & 1,98 & 2,01 & 1,97 \\
\hline $\mathrm{Na}$ & 0,07 & 0,07 & 0,03 & 0,02 & 0,03 & 0,08 & 0,10 & 0,09 \\
\hline $\mathrm{K}$ & 0,02 & 0,02 & 0,01 & 0,00 & 0,01 & 0,02 & 0,03 & 0,02 \\
\hline $\mathrm{S}$ & 15,07 & 15,07 & 15,05 & 15,00 & 15,03 & 15,09 & 15,14 & 15,09 \\
\hline $\mathrm{O}$ & 23,00 & 23,00 & 23,00 & 23,00 & 23,00 & 23,00 & 23,00 & 23,00 \\
\hline$X_{M g}$ & 0,71 & 0,72 & 0,67 & 0,69 & 0,69 & 0,68 & 0,64 & 0,66 \\
\hline
\end{tabular}

$C=$ Centro do cristal analisado. 


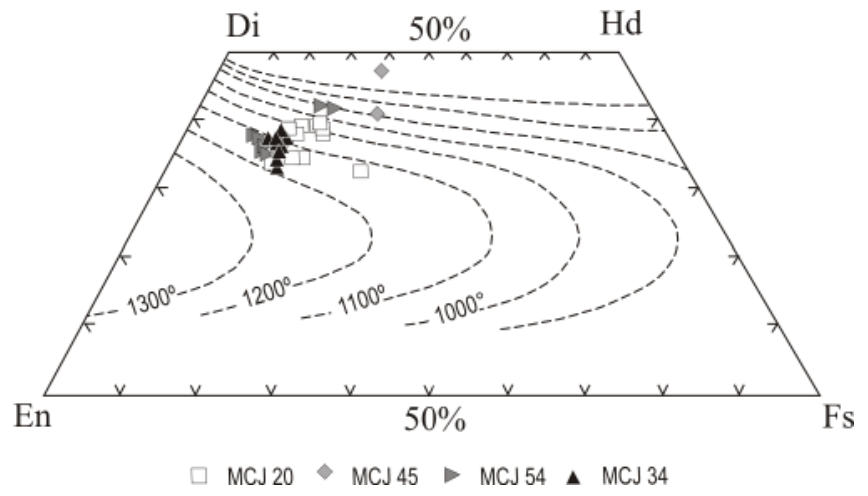

Figura 7 - Diagrama Di-Hd-En-Fs de Lindsley (1983) para estimar a possível temperatura de cristalização dos piroxênios. No caso de Cajamar os valores situamse entre 900 e $1.100^{\circ} \mathrm{C}$. são um pouco mais elevados que os de Spear 1980 e situam-se entre 400 e $500^{\circ} \mathrm{C}$, havendo destaque para os resultados obtidos com as amostras MCJ 53, que forneceu temperaturas de $460^{\circ} \mathrm{C}$, MCJ 3a, com valores entre 460 e $480^{\circ} \mathrm{C}$ e MCJ 45 que apresentou predominância de valores entre 480 e $500^{\circ} \mathrm{C}$.

Após essas estimativas passou-se a efetuar os cálculos empregando o software THERMOCALC, de Powell \& Holland (1988), sempre em presença de $\mathrm{H}_{2} \mathrm{O}$ (predominante) e $\mathrm{CO}_{2}$, calculando-se as condições físico químicas para atingir o equilíbrio entre as diferentes fases minerais e processando as diversas amostras analisadas, gerando-se diversos conjuntos de reações. Das amostras analisadas, apenas as $3 \mathrm{a}$ e 45 forneceram resultados satisfatórios, com menores desvios padrões, e a associação metamórfica utilizada é a considerada de pico metamórfico, ou seja: actinolita + albita + clinozoisita + clorita.

Tabela 2 - Análises dos feldspatos das rochas metamáficas.

\begin{tabular}{|c|c|c|c|c|c|c|c|}
\hline Amostra & MCJ 3a & MCJ 3a & MCJ 64 & MCJ 64 & MCJ 77 & MCJ 45 & MCJ 45 \\
\hline & $\mathrm{C}$ & $\mathrm{C}$ & $\mathrm{C}$ & $\mathrm{C}$ & $\mathrm{C}$ & $\mathrm{C}$ & $\mathrm{C}$ \\
\hline $\mathrm{SiO}_{2}$ & 67,50 & 66,59 & 64,35 & 65,92 & 68,64 & 68,36 & 67,74 \\
\hline $\mathrm{TiO}_{2}$ & 0,07 & 0,00 & 0,04 & 0,03 & 0,19 & - & 0,03 \\
\hline $\mathrm{Al}_{2} \mathrm{O}_{3}$ & 20,03 & 20,11 & 20,30 & 19,59 & 19,83 & 19,72 & 19,94 \\
\hline $\mathrm{Fe}_{2} \mathrm{O}_{3}$ & 0,14 & 0,13 & 0,50 & 2,00 & 0,62 & 0,15 & 0,34 \\
\hline $\mathrm{FeO}$ & 0,00 & 0,00 & 0,00 & 0,00 & 0,00 & 0,00 & 0,00 \\
\hline $\mathrm{MnO}$ & 0,02 & 0,00 & 0,00 & 0,03 & 0,00 & 0,00 & 0,01 \\
\hline $\mathrm{MgO}$ & 0,02 & 0,11 & 0,14 & 0,81 & 0,20 & 0,01 & - \\
\hline $\mathrm{BaO}$ & 0,02 & 0,00 & 0,00 & 0,09 & 0,03 & 0,05 & 0,06 \\
\hline $\mathrm{CaO}$ & 0,51 & 1,13 & 0,14 & 0,17 & 0,34 & 0,32 & 0,69 \\
\hline $\mathrm{Na}_{2} \mathrm{O}$ & 11,46 & 11,06 & 3,95 & 10,38 & 11,56 & 11,22 & 11,21 \\
\hline $\mathrm{K}_{2} \mathrm{O}$ & 0,12 & 0,07 & 10,28 & 1,22 & 0,05 & 0,47 & 0,05 \\
\hline Total & 99,88 & 99,19 & 99,71 & 100,22 & 101,47 & 100,30 & 100,06 \\
\hline $\mathrm{Si}$ & 11,84 & 11,80 & 11,70 & 11,65 & 11,84 & 11,92 & 11,86 \\
\hline $\mathrm{Al}$ & 4,14 & 4,19 & 4,35 & 4,08 & 4,03 & 4,06 & 4,11 \\
\hline $\mathrm{Fe}^{3+}$ & 0,02 & 0,02 & 0,07 & 0,27 & 0,08 & 0,02 & 0,04 \\
\hline $\mathrm{Ti}$ & 0,01 & 0,00 & 0,01 & 0,00 & 0,03 & 0,00 & 0,00 \\
\hline $\mathrm{Fe}^{2+}$ & 0,00 & 0,00 & 0,00 & 0,00 & 0,00 & 0,00 & 0,00 \\
\hline $\mathrm{Mn}$ & 0,00 & 0,00 & 0,00 & 0,00 & 0,00 & 0,00 & 0,00 \\
\hline $\mathrm{Mg}$ & 0,00 & 0,03 & 0,04 & 0,21 & 0,05 & 0,00 & 0,00 \\
\hline $\mathrm{Ba}$ & 0,00 & 0,00 & 0,00 & 0,01 & 0,00 & 0,00 & 0,00 \\
\hline $\mathrm{Ca}$ & 0,10 & 0,21 & 0,03 & 0,03 & 0,06 & 0,06 & 0,13 \\
\hline $\mathrm{Na}$ & 3,90 & 3,79 & 0,39 & 3,56 & 3,87 & 3,80 & 3,80 \\
\hline $\mathrm{K}$ & 0,03 & 0,02 & 2,39 & 0,27 & 0,01 & 0,11 & 0,01 \\
\hline Soma & 20,03 & 20,02 & 18,97 & 20,08 & 20,00 & 19,98 & 19,96 \\
\hline $\mathrm{O}$ & 32,00 & 32,00 & 32,00 & 32,00 & 32,00 & 32,00 & 32,00 \\
\hline An & 2,39 & 5,33 & 1,00 & 0,83 & 1,60 & 1,51 & 3,27 \\
\hline $\mathrm{Ab}$ & 96,96 & 94,30 & 14,03 & 92,08 & 98,13 & 95,84 & 96,43 \\
\hline Or & 0,65 & 0,37 & 84,97 & 7,10 & 0,28 & 2,65 & 0,30 \\
\hline
\end{tabular}

C = Centro do cristal analisado. 
Tabela 3 - Análises dos piroxênios das rochas metamáficas.

\begin{tabular}{|c|c|c|c|c|c|c|c|}
\hline Amostra & MCJ 54 & MCJ 20 & MCJ 20 & MCJ 45 & MCJ 45 & MCJ 34 & MCJ 34 \\
\hline & $\mathrm{C}$ & $\mathrm{C}$ & $\mathrm{C}$ & B & $\mathrm{C}$ & $\mathrm{C}$ & $\mathrm{C}$ \\
\hline $\mathrm{SiO}_{2}$ & 52,02 & 50,61 & 50,75 & 52,56 & 52,25 & 52,65 & 51,06 \\
\hline $\mathrm{TiO}_{2}$ & 0,40 & 0,40 & 0,46 & 0,36 & 0,34 & 0,26 & 0,56 \\
\hline $\mathrm{Al}_{2} \mathrm{O}_{3}$ & 2,12 & 2,80 & 2,93 & 2,03 & 1,92 & 2,29 & 2,23 \\
\hline $\mathrm{FeO}$ & 7,28 & 9,27 & 9,45 & 7,64 & 7,83 & 5,57 & 9,78 \\
\hline $\mathrm{Fe}_{2} \mathrm{O}_{3}$ & 0,00 & 0,00 & 0,00 & 0,00 & 0,00 & 0,00 & 0,00 \\
\hline $\mathrm{Cr}_{2} \mathrm{O}_{3}$ & 0,17 & 0,35 & 0,28 & 0,10 & 0,12 & 0,55 & 0,02 \\
\hline $\mathrm{MnO}$ & 0,17 & 0,29 & 0,30 & 0,17 & 0,18 & 0,13 & 0,47 \\
\hline $\mathrm{NiO}$ & 0,00 & 0,00 & 0,00 & 0,00 & 0,00 & 0,00 & 0,00 \\
\hline $\mathrm{MgO}$ & 16,82 & 14,92 & 14,52 & 17,23 & 17,52 & 18,02 & 13,36 \\
\hline $\mathrm{CaO}$ & 20,55 & 21,27 & 21,25 & 20,29 & 19,84 & 21,02 & 22,25 \\
\hline $\mathrm{Na}_{2} \mathrm{O}$ & 0,20 & 0,23 & 0,22 & 0,20 & 0,21 & 0,16 & 0,31 \\
\hline $\mathrm{K}_{2} \mathrm{O}$ & 0,01 & 0,00 & 0,00 & 0,00 & 0,00 & 0,01 & 0,01 \\
\hline Total & 99,72 & 100,14 & 100,16 & 100,58 & 100,21 & 100,66 & 100,04 \\
\hline $\mathrm{Si}$ & 1,92 & 1,88 & 1,88 & 1,92 & 1,91 & 1,91 & 1,91 \\
\hline $\mathrm{Ti}$ & 0,01 & 0,01 & 0,01 & 0,01 & 0,01 & 0,01 & 0,02 \\
\hline $\mathrm{Al}$ & 0,09 & 0,12 & 0,13 & 0,09 & 0,08 & 0,10 & 0,10 \\
\hline $\mathrm{Cr}$ & 0,01 & 0,01 & 0,01 & 0,00 & 0,00 & 0,02 & 0,00 \\
\hline $\mathrm{Fe}^{3+}$ & 0,07 & 0,11 & 0,09 & 0,07 & 0,08 & 0,07 & 0,08 \\
\hline $\mathrm{Fe}^{2+}$ & 0,16 & 0,18 & 0,21 & 0,16 & 0,15 & 0,10 & 0,23 \\
\hline $\mathrm{Mg}$ & 0,92 & 0,82 & 0,80 & 0,94 & 0,96 & 0,97 & 0,74 \\
\hline $\mathrm{Mn}$ & 0,01 & 0,01 & 0,01 & 0,01 & 0,01 & 0,00 & 0,02 \\
\hline $\mathrm{Ca}$ & 0,81 & 0,84 & 0,85 & 0,79 & 0,78 & 0,82 & 0,89 \\
\hline $\mathrm{Na}$ & 0,01 & 0,02 & 0,02 & 0,01 & 0,02 & 0,01 & 0,02 \\
\hline Soma & 4,00 & 4,00 & 4,00 & 4,00 & 3,99 & 4,00 & 4,00 \\
\hline $\mathrm{O}$ & 6,00 & 6,00 & 6,00 & 6,00 & 6,00 & 6,00 & 6,00 \\
\hline$X_{M g}$ & 0,85 & 0,82 & 0,80 & 0,85 & 0,86 & 0,91 & 0,76 \\
\hline
\end{tabular}

$C=$ Centro do cristal analisado. $B=$ Borda do cristal analisado.

Pela análise dos resultados é possível considerar como valores de pico metamórfico os resultados obtidos para a amostra MCJ 3a, considerando o estado de equilíbrio mineralógico e textural exibido por esta amostra:

$$
\mathrm{P}=8,2 \pm 2,2 \text { kbar e } \mathrm{T}=487 \pm 42^{\circ} \mathrm{C}
$$

Essa mesma amostra forneceu também um segundo grupo de resultados que indicam, possivelmente, um reequilíbrio em condições mais brandas e que são:

$$
\mathbf{P}=\mathbf{5 , 7} \pm \mathbf{2 , 0} \text { kbar e } \mathrm{T}=\mathbf{3 8 2} \pm \mathbf{4 0}{ }^{\circ} \mathrm{C}
$$

Para a amostra MCJ 45, situada na porção central da área, as temperaturas de pico são mantidas, mas as pressões são menores:

\section{$\mathrm{P}=\mathbf{4 , 7} \pm \mathbf{1 , 6} \mathrm{kbar} \mathrm{e} \mathrm{T}=\mathbf{4 5 0} \pm \mathbf{6 8}^{\circ} \mathrm{C}$}

Em uma amostra que ocorre mais a norte, ponto MCJ 77, os valores são ainda mais baixos e refletem as transformações retrometamórficas, considerando que este local foi bastante afetado pelos processos de cisalhamento:

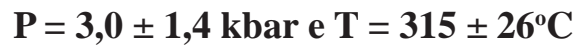

Para a obtenção desses resultados são envolvidos os termos: Fe - actinolita, pargasita, tschermackita, albita, epidoto, clinozoisita, clinocloro, dafolita, amesita e $\mathrm{H}_{2} \mathrm{O}\left(\mathrm{a}_{\mathrm{H} 2 \mathrm{O}}=1\right)$, no sistema $\mathrm{SiO}_{2}-\mathrm{Al}_{2} \mathrm{O}_{3}-\mathrm{Fe}_{2} \mathrm{O}_{3}$ - $\mathrm{FeO}-\mathrm{MgO}-\mathrm{CaO}-\mathrm{Na}_{2} \mathrm{O}-\mathrm{H}_{2} \mathrm{O}$. O conjunto das reações linearmente independentes, fornecidas pelo programa THERMOCALC encontra-se no Apêndice 1.

A ausência de plagioclásio e hornblenda, nas associações metamáficas estudadas, confirma o pico metamórfico dentro das condições ora obtidas.

Outras amostras utilizadas para cálculo forneceram valores de $\mathrm{T}$ e $\mathrm{P}$ dispersos, com desvio padrão muito alto, e não puderam ser aproveitadas. 
Tabela 4 - Análises de epidoto das rochas metamáficas.

\begin{tabular}{|c|c|c|c|c|c|c|c|c|}
\hline Amostra & MCJ 3a & MCJ 3a & MCJ 64 & MCJ 64 & MCJ 77 & MCJ 77 & MCJ 45 & MCJ 45 \\
\hline & $\mathrm{C}$ & B & B & $\mathrm{C}$ & B & $\mathrm{C}$ & $\mathrm{C}$ & $\mathrm{C}$ \\
\hline $\mathrm{SiO}_{2}$ & 37,36 & 37,90 & 38,11 & 37,58 & 38,48 & 38,42 & 37,25 & 37,54 \\
\hline $\mathrm{TiO}_{2}$ & 0,15 & 0,13 & 0,00 & 0,00 & 0,00 & 0,11 & 0,08 & 0,06 \\
\hline $\mathrm{Al}_{2} \mathrm{O}_{3}$ & 23,02 & 26,63 & 26,51 & 24,28 & 27,03 & 26,95 & 22,59 & 23,82 \\
\hline $\mathrm{Cr}_{2} \mathrm{O}_{3}$ & 0,00 & 0,00 & 0,00 & 0,00 & 0,00 & 0,00 & 0,00 & 0,00 \\
\hline $\mathrm{Fe}_{2} \mathrm{O}_{3}$ & 14,38 & 9,34 & 9,25 & 12,03 & 8,84 & 8,95 & 14,26 & 12,93 \\
\hline $\mathrm{FeO}$ & 0,00 & 0,00 & 0,00 & 0,00 & 0,00 & 0,00 & 0,00 & 0,00 \\
\hline $\mathrm{MnO}$ & 0,14 & 0,07 & 0,02 & 0,02 & 0,09 & 0,07 & 0,12 & 0,08 \\
\hline $\mathrm{MgO}$ & 0,02 & 0,02 & 0,00 & 0,03 & 0,20 & 0,10 & 0,00 & 0,02 \\
\hline $\mathrm{CaO}$ & 23,73 & 24,28 & 24,24 & 24,00 & 24,21 & 24,45 & 23,90 & 24,04 \\
\hline $\mathrm{Na}_{2} \mathrm{O}$ & 0,00 & 0,00 & 0,00 & 0,00 & 0,00 & 0,00 & $0,00-$ & 0,00 \\
\hline $\mathrm{K}_{2} \mathrm{O}$ & 0,00 & 0,00 & 0,00 & 0,00 & 0,00 & 0,00 & 0,00 & 0,00 \\
\hline Total & 98,80 & 98,37 & 98,14 & 97,93 & 98,85 & 99,04 & 98,21 & 98,49 \\
\hline $\mathrm{Si}$ & 3,09 & 3,09 & 3,11 & 3,10 & 3,11 & 3,10 & 3,10 & 3,09 \\
\hline $\mathrm{Al}$ & 2,24 & 2,55 & 2,54 & 2,36 & 2,57 & 2,56 & 2,21 & 2,31 \\
\hline $\mathrm{Ti}$ & 0,01 & 0,01 & 0,00 & 0,00 & 0,00 & 0,01 & 0,01 & 0,00 \\
\hline $\mathrm{Fe}^{3+}$ & 0,89 & 0,57 & 0,57 & 0,75 & 0,54 & 0,54 & 0,89 & 0,80 \\
\hline $\mathrm{Mg}$ & 0,00 & 0,00 & 0,00 & 0,00 & 0,02 & 0,01 & 0,00 & 0,00 \\
\hline $\mathrm{Fe}^{2+}$ & 0,00 & 0,00 & 0,00 & 0,00 & 0,00 & 0,00 & 0,00 & 0,00 \\
\hline $\mathrm{Mn}$ & 0,01 & 0,01 & 0,00 & 0,00 & 0,01 & 0,01 & 0,01 & 0,01 \\
\hline $\mathrm{Ca}$ & 2,10 & 2,12 & 2,12 & 2,12 & 2,09 & 2,11 & 2,13 & 2,12 \\
\hline Soma & 8,33 & 8,34 & 8,33 & 8,34 & 8,34 & 8,34 & 8,34 & 8,34 \\
\hline $\mathrm{O}$ & 13,00 & 13,00 & 13,00 & 13,00 & 13,00 & 13,00 & 13,00 & 13,00 \\
\hline$X_{M g}$ & 0,00 & 0,00 & 0,00 & 0,00 & 0,04 & 0,02 & 0,00 & 0,00 \\
\hline
\end{tabular}

$C=$ Centro do cristal analisado. $B=$ Borda do cristal analisado.

$A l I V=0 . A l V I=2($ default 13 O. OH. F $)$

METAMORFISMO Na área estudada de Cajamar, as rochas do Grupo São Roque são compostas, na maior parte, por metassedimentos siliciclásticos, representados principalmente por filitos, além de metarenitos, metacalcários e metabasitos, com associações típicas da fácies xistos verdes.

As rochas máficas (basalto e/ou gabro), com assinatura do tipo MORB, constituídas dominantemente por minerais anidros, estáveis a altas temperaturas, quando submetidas a metamorfismo regional hidrotermal (fundo oceânico) passam inicialmente por um processo de hidratação, com liberação de calor e formação de minerais hidratados de baixa temperatura. Essa associação vai ser gradativamente transformada em outra do tipo: albita + clorita + zoisita + quartzo \pm carbonato \pm titanita, da fácies xistos verdes inferior ou xistos verdes, cuja temperatura raramente ultrapassa os $500^{\circ} \mathrm{C}$.

A ausência de hornblenda nessas rochas limita os valores máximos de temperatura a aproximadamente $480^{\circ} \mathrm{C}$, segundo Bégin (1992) e Bégin \& Carmichael (1992), sendo que os valores de pressão podem chegar a $7 \mathrm{kbar}$, com valores máximos entre 6 e 9 kbar, segundo Spear (1993).
Actinolita, representada por variedade com baixos teores de Al, é o primeiro anfibólio a se formar envolvendo reação do tipo: Clorita (com baixo $\mathrm{Al})+$ carbonato (calcita, dolomita ou ankerita) + óxidos $=$ actinolita \pm zoisita $+\mathrm{CO}_{2}+\mathrm{H}_{2} \mathrm{O}$ (Spear 1993).

Reação desse tipo origina a associação diagnóstica da fácies xistos verdes representada por: clorita + albita + zoisita + actinolita + quartzo \pm carbonato (calcita, dolomita ou ankerita) \pm titanita.

Para o caso das metamáficas de Cajamar, após as primeiras alterações hidrotermais que levaram ao início das transformações do piroxênio e do plagioclásio, com o posterior soterramento de todo o pacote, incluindo os metassedimentos, ocorreu a estabilização das associações metamórficas, representadas por anfibólio cálcico (actinolita), albita, clorita, epidoto e titanita e que atingiu o pico metamórfico a aproximadamente $487^{\circ} \mathrm{C}$ de temperatura, com a pressão atingindo valores em torno de 8,2 kbar. Esses valores são típicos da fácies xistos verdes em seu limite superior com a fácies anfibolito.

CONCLUSÕES As rochas metamáficas da região de Cajamar são derivadas de uma suíte basáltica que 
Tabela 5 - Análises de cloritas das rochas metamáficas.

\begin{tabular}{|c|c|c|c|c|c|c|c|}
\hline Amostra & MCJ 45 & MCJ 64 & MCJ 77 & MCJ 77 & MCJ 3a & MCJ 3a & MCJ 3a \\
\hline & $\mathrm{C}$ & $\mathrm{C}$ & $\mathrm{C}$ & $\mathrm{C}$ & $\mathrm{C}$ & $\mathrm{C}$ & $\mathrm{C}$ \\
\hline $\mathrm{SiO}_{2}$ & 26,43 & 25,68 & 26,54 & 26,36 & 27,29 & 26,35 & 27,02 \\
\hline $\mathrm{TiO}_{2}$ & 0,00 & 0,00 & 0,00 & 0,06 & 0,12 & 0,05 & 0,07 \\
\hline $\mathrm{Al}_{2} \mathrm{O}_{3}$ & 20,02 & 19,98 & 20,48 & 19,67 & 18,74 & 19,55 & 19,17 \\
\hline $\mathrm{Cr}_{2} \mathrm{O}_{3}$ & 0,00 & 0,00 & 0,00 & 0,00 & 0,00 & 0,00 & 0,00 \\
\hline $\mathrm{FeO}$ & 23,77 & 28,86 & 23,66 & 23,80 & 23,03 & 23,06 & 23,08 \\
\hline $\mathrm{Fe}_{2} \mathrm{O}_{3}$ & 0,00 & 0,00 & 0,00 & 0,00 & 0,00 & 0,00 & 0,00 \\
\hline $\mathrm{MnO}$ & 0,26 & 0,37 & 0,30 & 0,30 & 0,13 & 0,25 & 0,24 \\
\hline $\mathrm{MgO}$ & 16,08 & 13,44 & 15,90 & 16,42 & 17,94 & 17,85 & 18,23 \\
\hline $\mathrm{CaO}$ & 0,14 & 0,02 & 0,08 & 0,12 & 0,08 & 0,07 & 0,07 \\
\hline $\mathrm{Na}_{2} \mathrm{O}$ & 0,02 & 0,02 & 0,00 & 0,02 & 0,00 & 0,03 & 0,00 \\
\hline $\mathrm{K}_{2} \mathrm{O}$ & 0,00 & 0,02 & 0,00 & 0,03 & 0,16 & 0,00 & 0,00 \\
\hline $\mathrm{F}$ & 0,04 & 0,05 & 0,02 & 0,00 & 0,02 & 0,02 & 0,01 \\
\hline $\mathrm{Cl}$ & 0,00 & - & 0,01 & 0,00 & 0,00 & 0,02 & 0,01 \\
\hline Total & 86,74 & 88,43 & 86,97 & 86,77 & 87,50 & 87,24 & 87,90 \\
\hline $\mathrm{Si}$ & 5,59 & 5,48 & 5,58 & 5,58 & 5,70 & 5,52 & 5,61 \\
\hline $\mathrm{Al}$ & 4,98 & 5,02 & 5,07 & 4,90 & 4,61 & 4,83 & 4,69 \\
\hline $\mathrm{Ti}$ & 0,00 & 0,00 & 0,00 & 0,01 & 0,02 & 0,01 & 0,01 \\
\hline $\mathrm{Fe}^{3+}$ & 0,00 & 0,00 & 0,00 & 0,00 & 0,00 & 0,00 & 0,00 \\
\hline $\mathrm{Fe}^{2+}$ & 4,20 & 5,15 & 4,16 & 4,21 & 4,02 & 4,04 & 4,01 \\
\hline $\mathrm{Cr}$ & 0,00 & 0,00 & 0,00 & 0,00 & 0,00 & 0,00 & 0,00 \\
\hline $\mathrm{Mn}$ & 0,05 & 0,07 & 0,05 & 0,05 & 0,02 & 0,05 & 0,04 \\
\hline $\mathrm{Mg}$ & 5,07 & 4,27 & 4,99 & 5,18 & 5,58 & 5,58 & 5,64 \\
\hline $\mathrm{Ca}$ & 0,03 & 0,01 & 0,02 & 0,03 & 0,02 & 0,02 & 0,02 \\
\hline $\mathrm{Na}$ & 0,01 & 0,01 & 0,00 & 0,01 & 0,00 & 0,01 & 0,00 \\
\hline $\mathrm{K}$ & 0,00 & 0,00 & 0,00 & 0,01 & 0,04 & 0,00 & 0,00 \\
\hline Soma & 19,92 & 20,01 & 19,87 & 19,97 & 20,00 & 20,05 & 20,03 \\
\hline $\mathrm{O}$ & 22,00 & 22,00 & 22,00 & 22,00 & 22,00 & 22,00 & 22,00 \\
\hline$X_{\mathrm{Mg}}$ & 0,55 & 0,45 & 0,55 & 0,55 & 0,58 & 0,58 & 0,59 \\
\hline
\end{tabular}

$C=$ Centro do cristal analisado.

ainda preserva a mineralogia primária, representada principalmente pelo clinopiroxênio e pelo plagioclásio na forma de pseudomorfos albitizados. O metamorfismo que afetou essas rochas produziu uma associação mineral composta por actinolita, albita, epidoto, clorita, titanita, quartzo e calcita, e se formou como consequência do metamorfismo regional de fácies xistos verdes que afetou esta área. A este metamorfismo sobrepôs-se um retrometamorfismo causado por intenso processo de cisalhamento, que na área encontra-se representado pela Zona de Cisalhamento de Jundiuvira.

Análises químicas dos minerais feitas por microssonda eletrônica evidenciam que o plagioclásio acha-se totalmente albitizado, o anfibólio tem composição bastante homogênea dentro do campo da actinolita, o epidoto é um tipo rico em $\mathrm{Fe}^{+3}$ e a clorita é representada pelas variedades corundofilita e ripidolita. As observações petrográficas mostram que o retrometamorfismo existente provocou modificações principalmente no epidoto e na clorita. Os dados de química mineral também.

$\mathrm{Na}$ tentativa de estabelecer os parâmetros de $\mathrm{P}$ e $\mathrm{T}$ para o metamorfismo regional, utilizou-se os geotermômetros de Spear (1980) e Blundy \& Holland (1990), obtendo-se temperaturas entre 300 e 420 e entre 400 e $500^{\circ} \mathrm{C}$, respectivamente, considerando o equilíbrio entre plagioclásio (albita) e actinolita.

Em cálculos mais acurados, feitos com o auxílio do programa THERMOCALC de Powell \& Holland (1988) observou-se certa variação nos resultados para o metamorfismo regional, sendo que os valores de $\mathrm{T}$ e $\mathrm{P}$ para o pico metamórfico (Ponto 3a) alcançaram $487^{\circ} \mathrm{C}$ e $8,2 \mathrm{kbar}$, respectivamente. Outros valores, mais baixos, foram também obtidos para $\mathrm{T}$ e $\mathrm{P}$ e que, provavelmente, representam locais em que o pico metamórfico não foi atingido, ou locais em que houve um reequilíbrio posterior da associação mineral. Observa-se que os valores mais baixos encontrados situam-se em torno de $450^{\circ} \mathrm{C}$ 
de $\mathrm{T}$ e 4,7 kbar de $\mathrm{P}$ para o ponto 45 e $315^{\circ} \mathrm{C}$ de $\mathrm{T}$ e 3,0 kbar de P para o ponto 77. Desta forma, considerando a trajetória metamórfica obtida, pode-se inferir que essa região passou por um processo de descompressão quase isotérmica, durante o evento de soerguimento regional que trouxe o pacote de rochas, ora estudado, para os níveis crustais atuais.

Agradecimentos Os autores agradecem à FAPESP (proc. 03/04115-5) pelo auxílio financeiro.

\section{Referências}

Almeida F.F.M. de, Amaral G., Cordani U. G., Kawashita K. 1973. The Pre Cambrian evolution of the South American cratonic margin, south of Amazon river. In: Nairn, E. M. \& Stehli, F. G. The ocean basins and margins. New York, Plenun, p. 411-446.

Batista J.T., Artur A.C., Simões L.S.A., Campos E.C. 1987. Geologia das Folhas Cajamar e Jordanésia (1:25.000). Rio Claro, Convênio SICCT-Pró-Minério-UNESPIGCE, Relatório Final, $128 \mathrm{p}$.

Bégin N.J. 1992. Contrast mineral isograd sequences in metabasites of the Cape Smith Belt, northern Québec, Canada: three news bathograds for mafic rocks. J. Metamorphic Geol., 10:685-704.

Bégin N.J. \& Carmichael D.M. 1992. Textural and compositional relationships of $\mathrm{Ca}$-amphiboles in metabasites of the Cape Smith Belt, northern Québec: implications for a miscibility gap at medium pressure. $J$. Petrol., 33(6):1317-1343.

Bergmann M. 1988. Caracterização estratigráfica e estrutural da Seqüência Vulcanossedimentar do Grupo São Roque na região de Pirapora do Bom Jesus - São Paulo. Dissertação de Mestrado, Instituto de Geociências, Universidade de São Paulo, São Paulo, 167 p.

Blundy J.D. \& Holland T.J.B. 1990. Calcic amphibole equilibria and a new amphibole-plagioclase geothermometer. Contrib. Mineral. Petrol., 104:208-224.

Campos Neto M.C. 2000. Orogenic Systems from Southwestern Gondwana: an approach to BrasilianoPan-African cycle and orogenic collage in Southeastern Brazil. In: Cordani U. G., Milani E.J., Thomaz Filho A., Campos D.A. (eds.) Tectonic Evolution of South America. Rio de Janeiro, CPRM, p. 335-365.

Campos Neto M.C. \& Figueiredo M.C.H. 1995. The Rio Doce Orogeny, Southeastern Brazil. Journal of South American Earth Sciences, 8(2):143-162.

Carneiro C.D.R., Hasui Y., Dantas A.S.L. 1984. Contribuição ao estudo da litoestratigrafia do Grupo São Roque na faixa Jaraguá-Cristais - SP. In: SBG, Congresso Brasileiro de Geologia, 39, Anais, p. 3212-3226.

Carneiro C.D.R., Hasui Y., Nagata N., Lima M.O. 1985. Padrões de superposição de estruturas do Grupo São Roque na faixa Jaraguá-Cristais (SP). Rev. Bras. Geoc., 15(2):116-130.

Coutinho J.M.V. 1980. Mapa geológico da grande São Paulo. São Paulo, EMPLASA - Empresa Metropolitana de Planejamento da Grande São Paulo, mapa geológico, escala 1:100.000.

Figueiredo M.C.H., Bergmann M., Penalva F. 1982. Ocorrências de pillow lavas no Grupo São Roque, estado de São Paulo. Ciências da Terra, 2:6-8.

Hackspacher P.C., Dantas E.L., Spoladore A., Fetter A.H., Oliveira M.A.F. de. 2000. Evidence of Neoproterozoic
Backarc Basin Development in the Central Ribeira Belt, Southeastern Brazil: New Geochronological and Gechemical Constraints from the São Roque - Açungui Groups. Rev. Bras. Geoc., 30:110-114.

Hasui Y. 1975. Evolução polifásica do Pré-Cambriano a oeste de São Paulo. Bol. IG, 6:95-108.

Hasui Y., Carneiro C.D.R., Bistrichi C.A. 1980. Estruturas e tectônica do Pré-Cambriano de São Paulo e Paraná. An. Acad. Bras. Ci., 52(1):61-76.

Juliani C., Beljavskis P., Schorscher H.D. 1986. Petrogênese do vulcanismo e aspectos metalogenéticos associados: Grupo Serra do Itaberaba na região de São Roque, SP. In: SBG, Congresso Brasileiro de Geologia, 34, Anais, p. $730-747$.

Juliani C. \& Beljavskis P. 1995. Revisão da litoestratigrafia da faixa São Roque/Serra do Itaberaba (SP). Rev. IG., 16(1/2):33-58.

Juliani C., Hackspacher P.C., Dantas E.L., Fetter A.H. 2000. The Mesoproterozoic volcano-sedimentary Serra do Itaberaba Group of the central Ribeira Belt, São Paulo State, Brazil: implications for the age of the overlying São Roque Group. Rev. Bras. Geoc., 30(1):82-86.

Lazzari M.L. 1987. O metabasito de Pirapora do Bom Jesus, $S P$. Dissertação de Mestrado, Instituto de Geociências, Universidade de São Paulo, São Paulo, 96 p.

Leake B.E., Wooley A.R., Arps C.E.S., Birch W.D., Gilbert M.C., Grice J.D., Hawthorne F.C., Kato A., Kisch H.J., Krivovichev V.G., Linthout K., Laird J., Mandarino J.A., Maresch W.V., Nickel E.H., Rock N.M.S., Schumacher J.C., Smith D.C., Stephenson N.C.N., Ungaretti L., Whittaker E.J.W., Yozhi G. 1997. Nomenclature of amfiboles: Report of Subcommitee on Amphiboles of the International Mineralogical Association, Commission on New Minerals and Mineral Name. American Mineralogist, 82:1019-1037.

Lindsley D.H. 1983. Piroxene Termobarometry. American Mineralogist, 68:477-493.

Martin M.A.B. 2000. Geologia, petrografia e metamorfismo dos Grupos Serra do Itaberaba e São Roque a noroeste da cidade de São Paulo (SP). Dissertação de Mestrado, Instituto de Geociências, Universidade de São Paulo, São Paulo, 256 p.

Morimoto N. 1988. Nomenclature of pyroxenes. Min. Mag., 52:535-550.

Okamoto A. \& Toriumi M. 2001. Appication of differential thermodynamics (Gibbs' method) to amphibole zonings in the metabasic system. Contrib. Mineral. Petrol., 141:268-286.

Okamoto A. \& Toriumi M. 2004. Optimal mixing properties of calcic and subcalcic amphiboles: appilation of Gibbs method to the Sanbagawa schists, SW Japan. Contrib. Mineral. Petrol., 146:529-545. 
Oliveira M.A. F. de, Nardy A.J.R., Maniesi, V. 2002. Petrologia e Litogeoquímica das rochas metabásicas da região de Cajamar (SP). Geociências, 21(1-2):33-42.

Oliveira M.A.F. De, Melo R.P., Nardy A.J.R., Arab P.B., Trindade I. 2008. New U/Pb Palaeoproterozoic zircon age for the Cajamar metabasite, São Roque Group, Central Ribeira Belt, southeastern Brazil. In: South American Symposium on Isotope Geology, 6, Book of Abstracts, p. 71.

Powell R. \& Holland T.J.B. 1988. An internally consistent data set with uncertainties and correlations: 3: application methods, worked examples and a computer program. Journal of Metamorphic Geology, 6:370-415.

Sadowski G.R. \& Tassinari C.C.G. 1991. The São Roque Volcano-Sedimentary Sequence of Proterozoic Age. In: International Gondwana Symposium, 7, Excursion Guide Book, p. 26.

Santoro E., Carneiro C.D.R., Oliveira M. C.B., Hachiro J. 1988. Estrutura geológica da região de CajamarJordanésia, SP. Rev. Bras. Geoc., 8(3):353-361.

Spear F.S. 1980. $\mathrm{NaSi}=\mathrm{CaAl}$ exchange equilibrium between plagioclase and amphibole. Contrib. Mineral. Petrol., 72:33-41.

Spear F.S. 1993. Metamorfic Phases Equilibria and PressureTemperature-Times Paths. Washington, Mineralogical Society of America, $799 \mathrm{p}$.
Tassinari C.C.G., Munhá M.U., Ribeiro A., Correia C.T. 2001. Neoproterozoic oceans in the Ribeira Belt (southeastern Brazil): the Pirapora do Bom Jesus ophiolitic complex. Episodes, 24(2):245-251.

Teixeira L.A. \& Gaucher C. 2004. Bacias do estágio de transição dos setores meridional (parcial) e central da Província Mantiqueira. In: Mantesso-Neto, V., Bartorelli, A., Carneiro, C. D. R., Brito-Neves, B. B. (orgs.) Geologia do Continente Sul-Americano: evolução da obra de Fernando Flávio Marques de Almeida. São Paulo, Editora Beca, p. 503-525.

Töpfner C. 1996. Brasiliano granitoid in den BundessTaaten São Paulo und Minas Gerais, Brasilien-Eine vergleichende studie (zircontypologie, $\mathrm{U}-(\mathrm{Th})-\mathrm{Pb}$ und $\mathrm{Rb}-\mathrm{Sr}$ altersbestimungen). Doctoral Thesis, Institut für Algemeine und Angewandte Geologie der LudwigMaximiliams-Universität München, München, 258 p.

Van Schmus W.R., Tassinari C.C.G., Cordani U.G. 1986. Estudo geocronológico da parte inferior do Grupo São Roque. In: Congresso Brasileiro de Geologia, 34, Anais, p. 1399-1406.

Manuscrito ID 17529

Submetido em 19 de maio de 2011 Aceito em 13 de outubro de 2011

\section{APÊNDICE 1}

Conjunto de reações linearmente independentes, fornecidas pelo programa THERMOCALC.

Amostra 3a.

1) $\mathrm{tr}+8 \mathrm{an}+2 \mathrm{clin}=5 \mathrm{ts}+4 \mathrm{H} 2 \mathrm{O}$

2) $5 \mathrm{ts}+12 \mathrm{cz}+14 \mathrm{q}=3 \mathrm{tr}+28 \mathrm{an}+8 \mathrm{H} 2 \mathrm{O}$

3) $\mathrm{tr}+14 \mathrm{clin}+24 \mathrm{cz}+28 \mathrm{q}=25 \mathrm{ts}+44 \mathrm{H} 2 \mathrm{O}$

4) $\mathrm{clin}+6 \mathrm{cz}+7 \mathrm{q}=\operatorname{tr}+10 \mathrm{an}+6 \mathrm{H} 2 \mathrm{O}$

5) $3 \mathrm{clin}+6 \mathrm{cz}+7 \mathrm{q}=5 \mathrm{ts}+2 \mathrm{an}+10 \mathrm{H} 2 \mathrm{O}$

6) $5 \mathrm{ames}+12 \mathrm{cz}+14 \mathrm{q}=24 \mathrm{an}+4 \mathrm{clin}+10 \mathrm{H} 2 \mathrm{O}$

7) $\mathrm{daph}+6 \mathrm{cz}+7 \mathrm{q}=$ fact $+10 \mathrm{an}+6 \mathrm{H} 2 \mathrm{O}$

8) $3 \mathrm{tr}+8 \mathrm{an}+2 \mathrm{daph}=2 \mathrm{fact}+5 \mathrm{ts}+4 \mathrm{H} 2 \mathrm{O}$

9) $\operatorname{tr}+$ daph $=$ fact + clin

10) $15 \mathrm{tr}+14 \mathrm{daph}+24 \mathrm{cz}+28 \mathrm{q}=14 \mathrm{fact}+25 \mathrm{ts}+44 \mathrm{H} 2 \mathrm{O}$

11) fact $+8 \mathrm{an}+3 \mathrm{clin}=5 \mathrm{ts}+\mathrm{daph}+4 \mathrm{H} 2 \mathrm{O}$

12) fact $+15 \mathrm{clin}+24 \mathrm{cz}+28 \mathrm{q}=25 \mathrm{ts}+\mathrm{daph}+44 \mathrm{H} 2 \mathrm{O}$

13) $\mathrm{cz}+$ fep $=2 \mathrm{ep}$

14) daph $+12 \mathrm{ep}+7 \mathrm{q}=$ fact $+10 \mathrm{an}+6 \mathrm{fep}+6 \mathrm{H} 2 \mathrm{O}$

15) $5 \mathrm{ts}+24 \mathrm{ep}+14 \mathrm{q}=3 \mathrm{tr}+28 \mathrm{an}+12 \mathrm{fep}+8 \mathrm{H} 2 \mathrm{O}$

16) $\mathrm{tr}+14 \mathrm{clin}+48 \mathrm{ep}+28 \mathrm{q}=25 \mathrm{ts}+24 \mathrm{fep}+44 \mathrm{H} 2 \mathrm{O}$

17) $15 \mathrm{tr}+14 \mathrm{daph}+48 \mathrm{ep}+28 \mathrm{q}=14 \mathrm{fact}+25 \mathrm{ts}+24 \mathrm{fep}+44 \mathrm{H} 2 \mathrm{O}$

18) $\operatorname{clin}+12 \mathrm{ep}+7 \mathrm{q}=\mathrm{tr}+10 \mathrm{an}+6 \mathrm{fep}+6 \mathrm{H} 2 \mathrm{O}$

19) 3 clin $+12 \mathrm{ep}+7 \mathrm{q}=5 \mathrm{ts}+2 \mathrm{an}+6 \mathrm{fep}+10 \mathrm{H} 2 \mathrm{O}$

20) fact $+15 \mathrm{clin}+48 \mathrm{ep}+28 \mathrm{q}=25 \mathrm{ts}+$ daph $+24 \mathrm{fep}+44 \mathrm{H} 2 \mathrm{O}$

21) $5 \mathrm{ames}+24 \mathrm{ep}+14 \mathrm{q}=24 \mathrm{an}+4 \mathrm{clin}+12 \mathrm{fep}+10 \mathrm{H} 2 \mathrm{O}$

\section{Amostra 45}

1) $\operatorname{clin}+6 \mathrm{cz}+7 \mathrm{q}=\operatorname{tr}+10 \mathrm{an}+6 \mathrm{H} 2 \mathrm{O}$

2) 5 ames $+12 \mathrm{cz}+14 \mathrm{q}=24 \mathrm{an}+4 \mathrm{clin}+10 \mathrm{H} 2 \mathrm{O}$ 

3) daph $+6 \mathrm{cz}+7 \mathrm{q}=$ fact $+10 \mathrm{an}+6 \mathrm{H} 2 \mathrm{O}$
4) $\operatorname{tr}+$ daph $=$ fact + clin
5) $\mathrm{tr}+35 \mathrm{ab}+27 \mathrm{clin}+120 \mathrm{cz}=35 \mathrm{parg}+172 \mathrm{an}+134 \mathrm{H} 2 \mathrm{O}$
6) $3 \mathrm{tr}+4 \mathrm{an}+5 \mathrm{ab}+\mathrm{clin}=5 \mathrm{parg}+20 \mathrm{q}+2 \mathrm{H} 2 \mathrm{O}$
7) $5 \mathrm{parg}+6 \mathrm{cz}+27 \mathrm{q}=4 \mathrm{tr}+14 \mathrm{an}+5 \mathrm{ab}+4 \mathrm{H} 2 \mathrm{O}$
8) $13 \mathrm{tr}+25 \mathrm{ab}+7 \mathrm{clin}+12 \mathrm{cz}=25 \mathrm{parg}+86 \mathrm{q}+22 \mathrm{H} 2 \mathrm{O}$
9) $14 \mathrm{ab}+12 \mathrm{clin}+48 \mathrm{cz}=14 \mathrm{parg}+68 \mathrm{an}+\mathrm{ames}+54 \mathrm{H} 2 \mathrm{O}$
10) $5 \mathrm{ab}+4 \mathrm{clin}+18 \mathrm{cz}+\mathrm{q}=5 \mathrm{parg}+26 \mathrm{an}+20 \mathrm{H} 2 \mathrm{O}$
11) $\mathrm{cz}+$ fep $=2 \mathrm{ep}$
12) daph $+12 \mathrm{ep}+7 \mathrm{q}=$ fact $+10 \mathrm{an}+6 \mathrm{fep}+6 \mathrm{H} 2 \mathrm{O}$
13) $28 \mathrm{tr}+35 \mathrm{ab}+27 \mathrm{daph}+120 \mathrm{cz}=27 \mathrm{fact}+35 \mathrm{parg}+172 \mathrm{an}+134 \mathrm{H} 2 \mathrm{O}$
14) $4 \mathrm{tr}+4 \mathrm{an}+5 \mathrm{ab}+\mathrm{daph}=$ fact $+5 \mathrm{parg}+20 \mathrm{q}+2 \mathrm{H} 2 \mathrm{O}$
15) $20 \mathrm{tr}+25 \mathrm{ab}+7 \mathrm{daph}+12 \mathrm{cz}=7 \mathrm{fact}+25 \mathrm{parg}+86 \mathrm{q}+22 \mathrm{H} 2 \mathrm{O}$
16) $\mathrm{fact}+35 \mathrm{ab}+28 \mathrm{clin}+120 \mathrm{cz}=35 \mathrm{parg}+172 \mathrm{an}+$ daph $+134 \mathrm{H} 2 \mathrm{O}$
17) $3 \mathrm{fact}+4 \mathrm{an}+5 \mathrm{ab}+4 \mathrm{clin}=5 \mathrm{parg}+3 \mathrm{daph}+20 \mathrm{q}+2 \mathrm{H} 2 \mathrm{O}$
18) $13 \mathrm{fact}+25 \mathrm{ab}+20 \mathrm{clin}+12 \mathrm{cz}=25 \mathrm{parg}+13 \mathrm{daph}+86 \mathrm{q}+22 \mathrm{H} 2 \mathrm{O}$
19) $\mathrm{clin}+12 \mathrm{ep}+7 \mathrm{q}=\mathrm{tr}+10 \mathrm{an}+6 \mathrm{fep}+6 \mathrm{H} 2 \mathrm{O}$
20) $5 \mathrm{ames}+24 \mathrm{ep}+14 \mathrm{q}=24 \mathrm{an}+4 \mathrm{clin}+12 \mathrm{fep}+10 \mathrm{H} 2 \mathrm{O}$
21) $\mathrm{tr}+35 \mathrm{ab}+27 \mathrm{clin}+240 \mathrm{ep}=35 \mathrm{parg}+172 \mathrm{an}+120 \mathrm{fep}+134 \mathrm{H} 2 \mathrm{O}$
22) $28 \mathrm{tr}+35 \mathrm{ab}+27 \mathrm{daph}+240 \mathrm{ep}=27 \mathrm{fact}+35 \mathrm{parg}+172 \mathrm{an}+120 \mathrm{fep}+134 \mathrm{H} 2 \mathrm{O}$
23) $5 \mathrm{parg}+12 \mathrm{ep}+27 \mathrm{q}=4 \mathrm{tr}+14 \mathrm{an}+5 \mathrm{ab}+6 \mathrm{fep}+4 \mathrm{H} 2 \mathrm{O}$
24) $13 \mathrm{tr}+25 \mathrm{ab}+7 \mathrm{clin}+24 \mathrm{ep}=25 \mathrm{parg}+12 \mathrm{fep}+86 \mathrm{q}+22 \mathrm{H} 2 \mathrm{O}$
25) $20 \mathrm{tr}+25 \mathrm{ab}+7 \mathrm{daph}+24 \mathrm{ep}=7 \mathrm{fact}+25 \mathrm{parg}+12 \mathrm{fep}+86 \mathrm{q}+22 \mathrm{H} 2 \mathrm{O}$
26) $\mathrm{fact}+35 \mathrm{ab}+28 \mathrm{clin}+240 \mathrm{ep}=35 \mathrm{parg}+172 \mathrm{an}+$ daph $+120 \mathrm{fep}+134 \mathrm{H} 2 \mathrm{O}$
27) $5 \mathrm{ab}+4 \mathrm{clin}+36 \mathrm{ep}+\mathrm{q}=5 \mathrm{parg}+26 \mathrm{an}+18 \mathrm{fep}+20 \mathrm{H} 2 \mathrm{O}$
28) $13 \mathrm{fact}+25 \mathrm{ab}+20 \mathrm{clin}+24 \mathrm{ep}=25 \mathrm{parg}+13 \mathrm{daph}+12 \mathrm{fep}+86 \mathrm{q}+22 \mathrm{H} 2 \mathrm{O}$
29) $14 \mathrm{ab}+12 \mathrm{clin}+96 \mathrm{ep}=14 \mathrm{parg}+68 \mathrm{an}+$ ames $+48 \mathrm{fep}+54 \mathrm{H} 2 \mathrm{O}$

\section{Amostra 77}
1) $\mathrm{clin}+6 \mathrm{cz}+7 \mathrm{q}=\mathrm{tr}+10 \mathrm{an}+6 \mathrm{H} 2 \mathrm{O}$
2) $5 \mathrm{ames}+12 \mathrm{cz}+14 \mathrm{q}=24 \mathrm{an}+4 \mathrm{clin}+10 \mathrm{H} 2 \mathrm{O}$
3) $\mathrm{daph}+6 \mathrm{cz}+7 \mathrm{q}=$ fact $+10 \mathrm{an}+6 \mathrm{H} 2 \mathrm{O}$
4) $\operatorname{tr}+$ daph $=$ fact + clin
5) $\mathrm{tr}+35 \mathrm{ab}+27 \mathrm{clin}+120 \mathrm{cz}=35 \mathrm{parg}+172 \mathrm{an}+134 \mathrm{H} 2 \mathrm{O}$
6) $3 \mathrm{tr}+4 \mathrm{an}+5 \mathrm{ab}+\mathrm{clin}=5 \mathrm{parg}+20 \mathrm{q}+2 \mathrm{H} 2 \mathrm{O}$
7) $5 \mathrm{parg}+6 \mathrm{cz}+27 \mathrm{q}=4 \mathrm{tr}+14 \mathrm{an}+5 \mathrm{ab}+4 \mathrm{H} 2 \mathrm{O}$
8) $13 \mathrm{tr}+25 \mathrm{ab}+7 \mathrm{clin}+12 \mathrm{cz}=25 \mathrm{parg}+86 \mathrm{q}+22 \mathrm{H} 2 \mathrm{O}$
9) $14 \mathrm{ab}+12 \mathrm{clin}+48 \mathrm{cz}=14 \mathrm{parg}+68 \mathrm{an}+\mathrm{ames}+54 \mathrm{H} 2 \mathrm{O}$
10) $5 \mathrm{ab}+4 \mathrm{clin}+18 \mathrm{cz}+\mathrm{q}=5 \mathrm{parg}+26 \mathrm{an}+20 \mathrm{H} 2 \mathrm{O}$
11) $\mathrm{cz}+$ fep $=2$ ep
12) daph +12 ep $+7 q=$ fact $+10 a n+6 f e p+6 \mathrm{H} 2 \mathrm{O}$
13) $28 \mathrm{tr}+35 \mathrm{ab}+27 \mathrm{daph}+120 \mathrm{cz}=27 \mathrm{fact}+35 \mathrm{parg}+172 \mathrm{an}+134 \mathrm{H} 2 \mathrm{O}$
14) $4 \mathrm{tr}+4 \mathrm{an}+5 \mathrm{ab}+$ daph $=$ fact $+5 \mathrm{parg}+20 \mathrm{q}+2 \mathrm{H} 2 \mathrm{O}$
15) $20 \mathrm{tr}+25 \mathrm{ab}+7 \mathrm{daph}+12 \mathrm{cz}=7 \mathrm{fact}+25 \mathrm{parg}+86 \mathrm{q}+22 \mathrm{H} 2 \mathrm{O}$
16) $\mathrm{fact}+35 \mathrm{ab}+28 \mathrm{clin}+120 \mathrm{cz}=35 \mathrm{parg}+172 \mathrm{an}+$ daph $+134 \mathrm{H} 2 \mathrm{O}$
17) $3 \mathrm{fact}+4 \mathrm{an}+5 \mathrm{ab}+4 \mathrm{clin}=5 \mathrm{parg}+3 \mathrm{daph}+20 \mathrm{q}+2 \mathrm{H} 2 \mathrm{O}$
18) $13 \mathrm{fact}+25 \mathrm{ab}+20 \mathrm{clin}+12 \mathrm{cz}=25 \mathrm{parg}+13 \mathrm{daph}+86 \mathrm{q}+22 \mathrm{H} 2 \mathrm{O}$
19) $\mathrm{clin}+12 \mathrm{ep}+7 \mathrm{q}=\operatorname{tr}+10 \mathrm{an}+6 \mathrm{fep}+6 \mathrm{H} 2 \mathrm{O}$
20) 5 ames $+24 \mathrm{ep}+14 \mathrm{q}=24 \mathrm{an}+4 \mathrm{clin}+12 \mathrm{fep}+10 \mathrm{H} 2 \mathrm{O}$
21) $\mathrm{tr}+35 \mathrm{ab}+27 \mathrm{clin}+240 \mathrm{ep}=35 \mathrm{parg}+172 \mathrm{an}+120 \mathrm{fep}+134 \mathrm{H} 2 \mathrm{O}$
22) $28 \mathrm{tr}+35 \mathrm{ab}+27 \mathrm{daph}+240 \mathrm{ep}=27 \mathrm{fact}+35 \mathrm{parg}+172 \mathrm{an}+120 \mathrm{fep}+134 \mathrm{H} 2 \mathrm{O}$
23) $5 \mathrm{parg}+12 \mathrm{ep}+27 \mathrm{q}=4 \mathrm{tr}+14 \mathrm{an}+5 \mathrm{ab}+6 \mathrm{fep}+4 \mathrm{H} 2 \mathrm{O}$
24) $13 \mathrm{tr}+25 \mathrm{ab}+7 \mathrm{clin}+24 \mathrm{ep}=25 \mathrm{parg}+12 \mathrm{fep}+86 \mathrm{q}+22 \mathrm{H} 2 \mathrm{O}$
25) $20 \mathrm{tr}+25 \mathrm{ab}+7 \mathrm{daph}+24 \mathrm{ep}=7 \mathrm{fact}+25 \mathrm{parg}+12 \mathrm{fep}+86 \mathrm{q}+22 \mathrm{H} 2 \mathrm{O}$
26) fact $+35 \mathrm{ab}+28 \mathrm{clin}+240 \mathrm{ep}=35 \mathrm{parg}+172 \mathrm{an}+$ daph $+120 \mathrm{fep}+134 \mathrm{H} 2 \mathrm{O}$
27) $5 \mathrm{ab}+4 \mathrm{clin}+36 \mathrm{ep}+\mathrm{q}=5 \mathrm{parg}+26 \mathrm{an}+18 \mathrm{fep}+20 \mathrm{H} 2 \mathrm{O}$
28) $13 \mathrm{fact}+25 \mathrm{ab}+20 \mathrm{clin}+24 \mathrm{ep}=25 \mathrm{parg}+13 \mathrm{daph}+12 \mathrm{fep}+86 \mathrm{q}+22 \mathrm{H} 2 \mathrm{O}$
29) $14 \mathrm{ab}+12 \mathrm{clin}+96 \mathrm{ep}=14 \mathrm{parg}+68 \mathrm{an}+\mathrm{ames}+48 \mathrm{fep}+54 \mathrm{H} 2 \mathrm{O}$
Abreviatura dos minerais segundo Powell \& Holland (1988). 